\title{
Asymmetric craters on Vesta: Impact on sloping surfaces
}

\author{
K. Krohn ${ }^{\text {a,* }}$, R. Jaumann ${ }^{\text {a,b }}$, D. Elbeshausen ${ }^{c}$, T. Kneissl ${ }^{\text {b }}$, N. Schmedemann ${ }^{\text {b }}$, R. Wagner ${ }^{\text {, }}$, \\ J. Voigt ${ }^{a}$, K. Otto ${ }^{\text {a }}$, K.D. Matz ${ }^{\text {a }}$, F. Preusker ${ }^{\text {, }}$, T. Roatsch ${ }^{\text {a }}$, K. Stephan ${ }^{\text {a }}$, C.A. Raymond ${ }^{\text {, }}$, \\ C.T. Russell ${ }^{\mathrm{e}}$ \\ a Institute of Planetary Research, German Aerospace Center (DLR), Berlin, Germany \\ ${ }^{\mathrm{b}}$ Freie Universität Berlin, Inst. of Geosciences, Planetology and Remote Sensing, Germany \\ c Museum für Naturkunde, Leibniz-Institut für Evolutions- und Biodiversitätsforschung, Berlin, Germany \\ d Jet Propulsion Laboratory, California Institute of Technology, Pasadena, USA \\ e UCLA, Institute of Geophysics, Los Angeles, USA
}

\section{A R T I C L E I N F O}

Article history:

Received 2 January 2013

Received in revised form

26 January 2014

Accepted 7 April 2014

Keywords:

Vesta

Asymmetrical craters

Impact modeling

Crater formation on small bodies

Cratering

Processes

\begin{abstract}
A B S T R A C T
Cratering processes on planetary bodies happen continuously and cause the formation of a large variety of impact crater morphologies. On Vesta whose surface has been imaged at high resolution during a 14 months orbital mission by the Dawn spacecraft we identified a substantial number of craters with an asymmetrical shape. These craters, in total a number of 2892 ranging in diameter from $0.3 \mathrm{~km}$ to $43 \mathrm{~km}$, are characterized by a sharp crater rim on the uphill side and a smooth one on the downhill side. The formation of these unusual asymmetric impact craters is controlled by Vesta's remarkable topographic relief. In order to understand the processes creating such unusual crater forms on a planetary body with a topography like Vesta we carried out the following work packages: (1) the asymmetric craters show various morphologies and therefore can be subdivided into distinct classes by their specific morphologic details; (2) using a digital terrain model (DTM), the craters are grouped into bins of slope angles for further statistical analysis; (3) for a subset of these asymmetric craters, the size-frequency distributions of smaller craters superimposed on their crater floors and continuous ejecta are measured in order to derive cratering model ages for the selected craters and to constrain possible post-impact processes; (4) three-dimensional hydrocode simulations using the iSALE-3D code are applied to the data set in order to quantify the effects of topography on crater shape and ejecta distribution. We identified five different classes (A-E) of asymmetric craters. Primarily, we focus on class A in this work. The global occurrence of these crater classes compared with a slope map clearly shows that these asymmetric crater types exclusively form on slopes. We found that slopes, especially slopes $>20^{\circ}$, prevent the deposition of ejected material in the uphill direction, and slumping material superimposed the deposit of ejecta on the downhill side. The combination of these two processes explains the local accumulation of material in this direction. In the subset of asymmetric craters which we used for crater counts, our results show that no post-impact processes have taken place since floors and continuous ejecta in each crater show comparable cratering model ages within the uncertainties of the cratering chronology model. Therefore the formation, or modification, of the asymmetric crater forms by processes other than impact can be excluded with some certainty.
\end{abstract}

(c) 2014 Elsevier Ltd. All rights reserved.

\section{Introduction}

Observations on planetary surfaces have revealed that a large majority of impact craters have a shape that is circular in-plane. The reason why even the most oblique impacts produce circular craters is because of the hypervelocity nature of these events.

\footnotetext{
* Corresponding author.

E-mail address: Katrin.Krohn@dlr.de (K. Krohn).
}

During impact, a significant amount of energy is released into the target within a short period of time. The physical process of crater excavation is, thus, similar to the detonation of an explosive source and, therefore, results in a symmetric excavation flow and crater growth. This simplification, the so-called "impact and explosion analogy" (Holsapple, 1980; Oberbeck et al., 1977), only provides an explanation for the formation of circular and symmetric craters.

However, many observations have revealed evidence for the asymmetric crater growth of some impact structures, such as on the Moon (Plescia, 2012), on Lutetia, and on Vesta (Jaumann et al., 2012). 
The origin of these asymmetries is manifold and in most cases is still ambiguous. Generally, the formation of impact craters is treated for the case of more or less planar surfaces for simplicity but it can be assumed that asymmetries in the crater forms are a result of projectile trajectory (e.g., Plescia, 2012). Shallow impact angles could produce asymmetric ejecta distribution, often in a butterfly pattern with little or no ejecta on the uphill side. At very shallow angles, the crater becomes elongated (Gault and Wedekind, 1978). Additionally, topography (Elbeshausen and Wünnemann, 2011) or heterogeneous stratigraphy (e.g., Collins et al. 2008; Gulick et al. 2008) is often discussed as conditions capable of supporting asymmetric crater formation. Additionally, post-impact modification by volcanism (Schultz, 1977), tectonics (Gurov et al., 2007) or erosion (Simonds and Kieffer, 1993) might also overprint an initially circular impact structure and change it to an asymmetric shape.

The Dawn spacecraft (Russell and Raymond, 2011) entered the orbit of the inner main belt asteroid Vesta on July 17, 2011, and conducted an approximately 14 month science operation to characterize the geology, mineralogical composition, topography, shape, and internal structure of Vesta (Jaumann et al., 2012). The image data show many asymmetrical craters on Vesta.

Because there is no significant erosion and no tectonic activity on Vesta, the impacts should be oblique and/or topographically influenced. However, this still needs to be demonstrated. Thus, the major goals of this paper are twofold: First, we describe the morphology of these asymmetric craters. Second, we investigate whether topography played a dominant role in the formation of these craters.

After describing the methods used in Section 2, we present detailed information about the morphology of these asymmetric craters and attempt to classify their shapes. We use agedetermination techniques to show which of the observed morphological features can be associated with the impact crater. By comparing the distribution of the slopes within the spatial distribution of the asymmetric craters, we examine whether topography played the dominant role in the formation of the impact structures. Finally, we use three-dimensional numerical hydrocode modeling to gain insight into the crater formation process.

\section{Data and methods}

Both the Dawn Framing Camera data (FC;Sierks et al. (2011) and the HAMO digital terrain model (DTM; see supplemental material of Jaumann et al. (2012) for further description) were used for the analysis of the asymmetric crater distribution, mineralogy and ejecta distribution on Vesta. During the orbital phases, the FC mapped the surface with image scales of $\sim 260 \mathrm{~m} /$ pixel (FC) in the Survey phase, $\sim 60 \mathrm{~m} /$ pixel (FC) in the High Altitude Mapping Orbit (HAMO) and $\sim 20 \mathrm{~m} /$ pixel (FC) in the Low Altitude Mapping Orbit (LAMO). The topography of Vesta is derived from Dawn FC Stereo images (Jaumann et al., 2012). Dawn arrived in the Vestan southern summer, which allowed for a complete survey of the south polar and equatorial regions for Survey and HAMO data (Denevi et al., 2012).

For our investigations, we primarily used the HAMO, DTM, and LAMO data. The high-resolution LAMO data nearly covers the surface of Vesta, approximately $90 \%$ of the surface from $90^{\circ} \mathrm{S}$ up to $\sim 50^{\circ} \mathrm{N}$. With the complete coverage of HAMO data, we can observe the asymmetric craters quite well.

\subsection{Geologic investigations}

FC-LAMO images with resolutions of $20 \mathrm{~m} /$ pixel were used to identify asymmetric craters. To complete the survey, areas that lack FC-LAMO coverage were examined based on the FC-HAMO data with a resolution of $60 \mathrm{~m} /$ pixel. Due to the resolution of $20 \mathrm{~m} /$ pixel for the FC-LAMO data, we can clearly identify asymmetrical craters with diameters $\geq 300 \mathrm{~m}$. Craters with diameters less than $300 \mathrm{~m}$ cannot definitively be identified as asymmetric.

Asymmetric craters are morphologically characterized by asymmetrical shapes on sloping surfaces, e.g., mixtures of sharp and smooth crater rims, asymmetric interior morphology and ejecta distribution.

For our investigations, we (a) prepared a geomorphologic map to determine the ejecta distribution with the help of clear filter and multispectral color filter images derived from FC-LAMO data, (b) identified and digitized the outline of each asymmetric crater using the ESRI software package ArcGIS, (c) measured the crater diameters with the help of CraterTools (Kneissl et al., 2011), and (d) created a slope map with the ArcGIS slope tool using the DTM with $450 \mathrm{~m} /$ pixel resolution. To create the slope map, we used an ArcGIS tool to calculate the maximum rate of change in value from each cell to its neighbors. The steepest downhill descent from the cell is represented by the maximum change in elevation over the distance between the cell and its eight surrounding neighbors.

\subsection{Three-dimensional hydrocode simulations}

Numerical simulations are powerful tools that can be used to obtain insights into the dynamics of the cratering process. To consider the effect of topography, three-dimensional simulations are required. For this purpose, we used iSALE-3D, a three-dimensional, multi-material, multi-rheology hydrocode (Elbeshausen et al., 2009; Elbeshausen and Wünnemann, 2011a). iSALE-3D is capable of calculating hypervelocity impacts into topography (Elbeshausen and Wünnemann, 2011; Elbeshausen et al., 2012). It follows an ICE'd ALE (Implicit Continuous-Fluid Eulerian (ICE) and Arbitrary-Lagrangian-Eulerian (ALE)) approach, as described in Harlow and Amsden (1971) and Hirt et al. (1974), to solve the Navier-Stokes equations in a compressible manner; it uses finite-differences and finite-volume techniques on a staggered Cartesian mesh. Here, we are utilizing iSALE-3D in the Eulerian mode, which additionally requires the reconstruction of interfaces to allow for a precise calculation of material flows. This reconstruction can be performed with an adaptive approach using volume-of-fluid techniques (Benson, 2002; Gueyffier et al., 1999; Hirt and Nichols, 1981) as described in Elbeshausen and Wünnemann (2011). The code has been successfully validated against both laboratory experiments and other numerical codes (Davison et al., 2011; Pierazzo et al., 2008).

To study whether slopes may influence the cratering process of the observed asymmetric craters, we conducted some simulations of oblique impacts into slopes. The effect of topography on impact crater morphology is still far away from being understood and it is not the intention of our study to provide a fully quantified answer to all these effects. Previous numerical studies (Elbeshausen and Wünnemann, 2011b; Elbeshausen et al., 2012) revealed that it is a huge effort to obtain a quantitative description, even when assuming a simplified topography: crater morphology is influenced by (a) the height of the slope, (b) the slope angle, (c) the point of impact relative to the slope, (d) the impact direction and angle compared to the slope, (e) impact velocity, (f) rheology and properties of the slope material, and (g) many other constraints. Thus, trying to generate a quantitative description of the topographical effects would require several thousands of full 3D-simulations at a reasonable resolution. This is far away from being possible, even on today's computer infrastructures. Instead, our intention is here to investigate numerically whether the observed asymmetries in the crater shape and ejecta deposits can be - in principle - explained by the existence of a slope. 
For this purpose we chose simplified setup geometry, defined by a slope of $3.7 \mathrm{~km}$ height with an inclination angle of $45^{\circ}$. We calculated impacts of a $1-\mathrm{km}$ sized projectile at a velocity of $U=5 \mathrm{~km} \mathrm{~s}^{-1}$, which is a reasonable impact velocity for a lowgravity body $\left(g=0.22 \mathrm{~m} / \mathrm{s}^{2}\right.$ ) located in the asteroid belt, such as Vesta (Denevi et al., 2012). For simplicity, both the projectile and the target are assumed to be composed of dunite. To compute the thermodynamic state of the material, we used the Analytical Equation of State (ANEOS, see Thompson and Lauson (1972)) in a tabulated form for dunite. The strength of the material is determined, and a realistic calculation of the mechanical response of a geological material under high dynamic conditions is performed by the approach described in Collins et al. (2004), which also considers damage accumulation. Porosity (here: 25\%) is considered using the $\varepsilon$ - $\alpha$-compaction model described in Wünnemann et al. (2006). Temporal and local weakening is given by the mechanism of acoustic fluidization, as presented in Wünnemann and Ivanov (2003).

Based on these constraints, we conducted a set of simulations where we varied the impact angle $\alpha$ and the position of the impact (either on the lower or the upper part of the slope, or in the center). In this way, we investigated whether we could find a scenario that would produce results such as those observed on Vesta. So far, the direction of impact has always been towards the slope, as sketched in Fig. 1. The parameters used to define the rheology of the material are listed in Table 1.

\subsection{Age determination}

Relative and absolute ages of remaining ejecta blankets, material of the smooth crater rims as well as crater interiors were determined using crater size-frequency distributions (CSFDs). This method was carried out on LAMO imagery in combination with the DTM to understand the chronology of the asymmetric crater

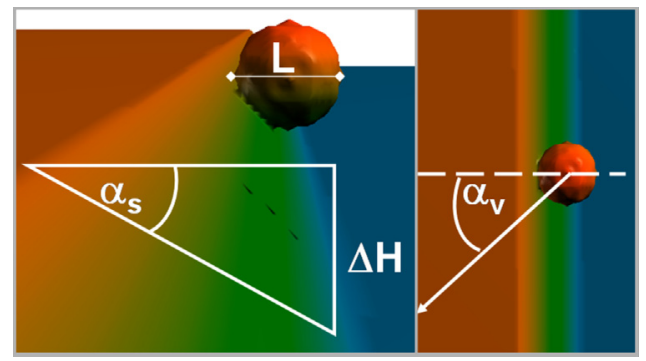

Fig. 1. Setup used for the numerical simulations. The slope is defined by its height, $\Delta H$, and its inclination $\alpha_{s}$. The impactor trajectory is given by the impact angle $\alpha$ (measured from horizontal) and an azimuthal angle, $\alpha_{\nu}$, which has been kept constant $\left(\alpha_{v}=0^{\circ}\right)$ in these simulations.

Table 1

Properties of projectile and target material used in hydrocodes simulations.

\begin{tabular}{ll}
\hline Material & Dunite $^{\mathrm{a}}$ \\
\hline Density & $2486.5 \mathrm{~kg} \mathrm{~m}^{-3}$ \\
Melting temperature & $1673 \mathrm{~K}^{-1} \mathrm{~K}^{-1}$ \\
Heat capacity & $1000 \mathrm{~J} \mathrm{~kg}^{-1}{ }^{-1}$ \\
Poisson ratio & 0.25 \\
Cohesion (damaged material) & $1 \mathrm{kPa}$ \\
Coefficient of friction (damaged material) & 0.5 \\
Cohesion (intact material) & $0.25 \mathrm{MPa}$ \\
Coefficient of friction (intact material) & 2.0 \\
Hugoniot elastic limit & $1 \mathrm{GPa}$ \\
Porosity & $25 \%$ \\
\hline
\end{tabular}

${ }^{\text {a }}$ Equation of state: ANEOS (see Thompson and Lauson, 1972). formation processes. We want to prove if the shape of these craters was caused by the cratering process itself or results from post-impact modification which happened a significant time after the crater formation.

Relative ages in terms of cumulative frequencies equal to, or larger than, a reference diameter of 1 and/or $10 \mathrm{~km}$ (e.g., Arvidson et al. (1979)) were obtained by fitting the recently derived production function for Vesta (Schmedemann et al., 2012, this issue). The Vesta production function is described by a polynomial of 11 th degree. It has been derived from the well-investigated lunar cratering record. High similarities between previously observed crater distributions on various asteroids, e.g., Gaspra, Ida, and Lutetia (Chapman et al., 1996a, 1996b; Marchi et al., 2012a), and the Moon (Hiesinger et al., 2002; Ivanov, 2008; Massironi et al., 2009; Neukum, 1983, 1984; Neukum et al., 1994, 2001; O'Brien and Greenberg, 2005; Schmedemann et al., 2012, this issue; Strom et al., 2005), led to the conclusion that a common family of primary impactors exists which originate in the asteroid Main Belt and which preferentially are responsible for cratering the surfaces of asteroids as well as the terrestrial planets in the inner solar system. Furthermore, the lunar crater size-frequency distribution is consistent with the Main Belt body size-frequency distribution of the crater-generating projectiles (Ivanov et al., 2001; Williams et al., this issue). The lunar production function is scaled to Vesta impact conditions by crater scaling laws (Ivanov, 2001). Secondary craters (clusters, chains, or irregularly shaped small craters) are excluded from our crater counts. Despite the differences, the relative trends remain the same and are sufficient to support the statements made here.

We obtained absolute ages in units of Giga-years (Ga) or Megayears (Ma) (Holden et al., 2011), using the cratering chronology model for Vesta derived by Schmedemann et al. (2012, this issue). We use the chronology model of Schmedemann et al. (2012, this issue) in this work because of (a) the strong correlation between measured crater size-frequency distributions and the potential impactor size-frequency distribution obtained from crater scaling; because of (b) the good agreement of $\mathrm{K} / \mathrm{Ar}-\mathrm{Ar}$ radiometric ages of HED meteorites (Bogard, 2011; Bogard and Garrison, 2003) with cratering model ages derived from various surface units on Vesta, which indicate a lunar-like time dependence for the Moon as inferred by Neukum et al. (1994), and because of (c) the lunar chronology is well documented by radiometric ages of rock materials (e.g., Neukum et al. (1994)).

At the time of writing, an alternative chronology based on dynamical models is not yet available. An early stage of such an alternative chronology has been presented by O'Brien et al. (2012), but this work is still in progress. For ages $>3.5 \mathrm{Ga}$, crater frequencies would be considerably lower in a dynamical modelbased chronology compared to a lunar-like chronology. This stems from the nearly linear characteristics of the chronology function of O'Brien et al. (2012). Thus, crater retention ages $>3.5 \mathrm{Ga}$ in a lunar-like chronology, would shift to higher ages and would be less correlated to the Ar-Ar ages in the chronology by O'Brien et al. (2012). However, for ages $<3.5 \mathrm{Ga}$, both chronologies are linear and basically identical. Thus, we do not expect differences of more than a factor of two between the two chronologies, if applied to our crater counts.

There is a considerable difference in the crater production functions that were used. The lunar-like function we use has, overall, more wavy characteristics and a steep slope of cumulative $\sim-3$ at small sizes. The crater production function used by Marchi et al. (2012b) is derived from the average Main Belt, as published by Bottke et al. (2005). It is not as wavy as the lunar-like crater production function and it has a somewhat shallower slope for small crater sizes, on the order of $\sim-2.5$ cumulative. Depending on the actual used crater size, these 

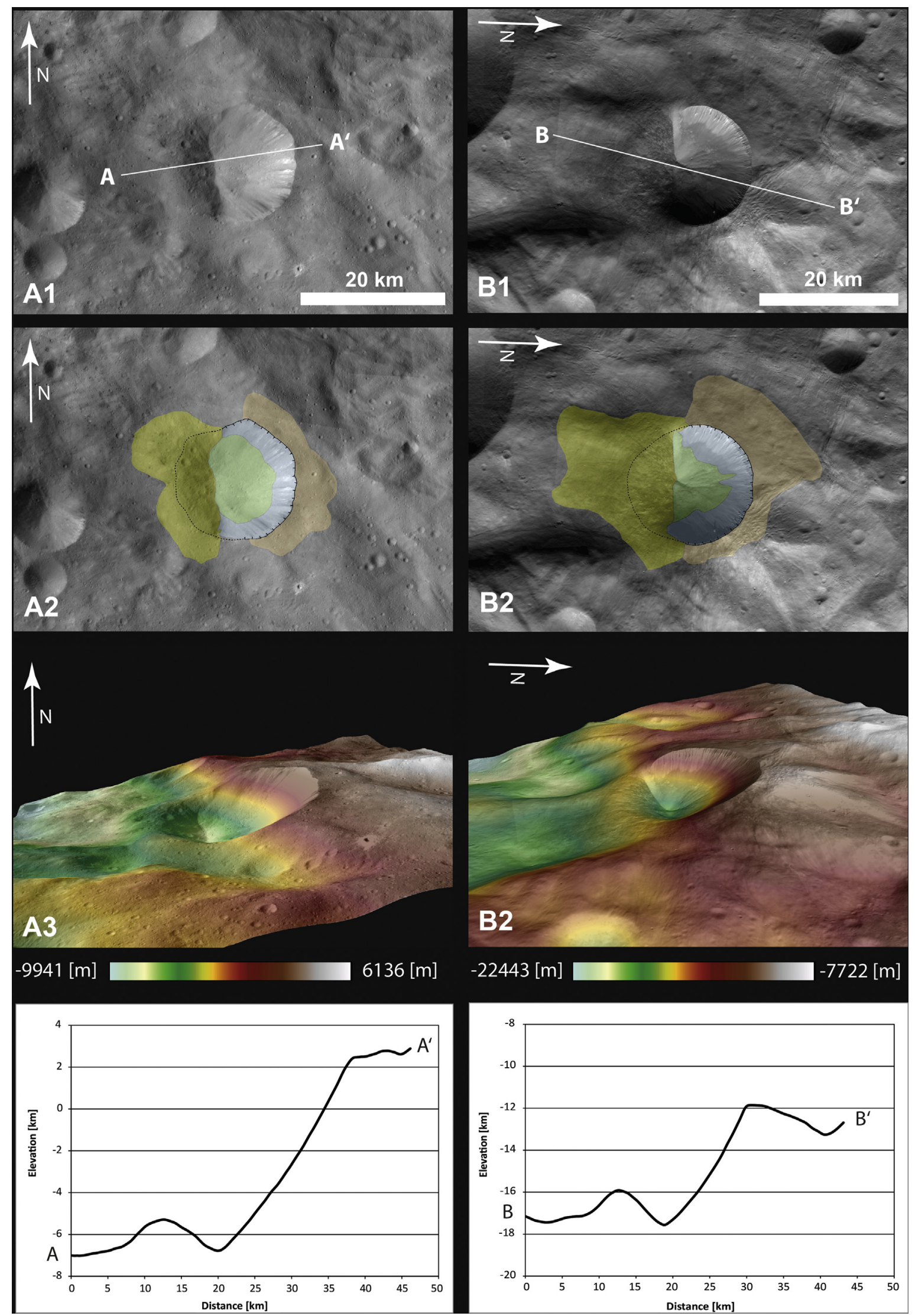

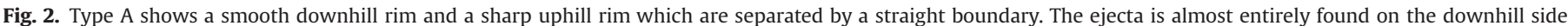

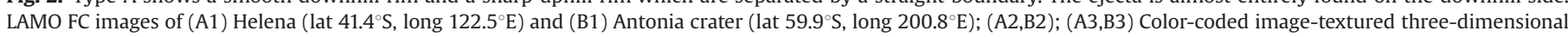
perspective view showing the height difference in elevation. 


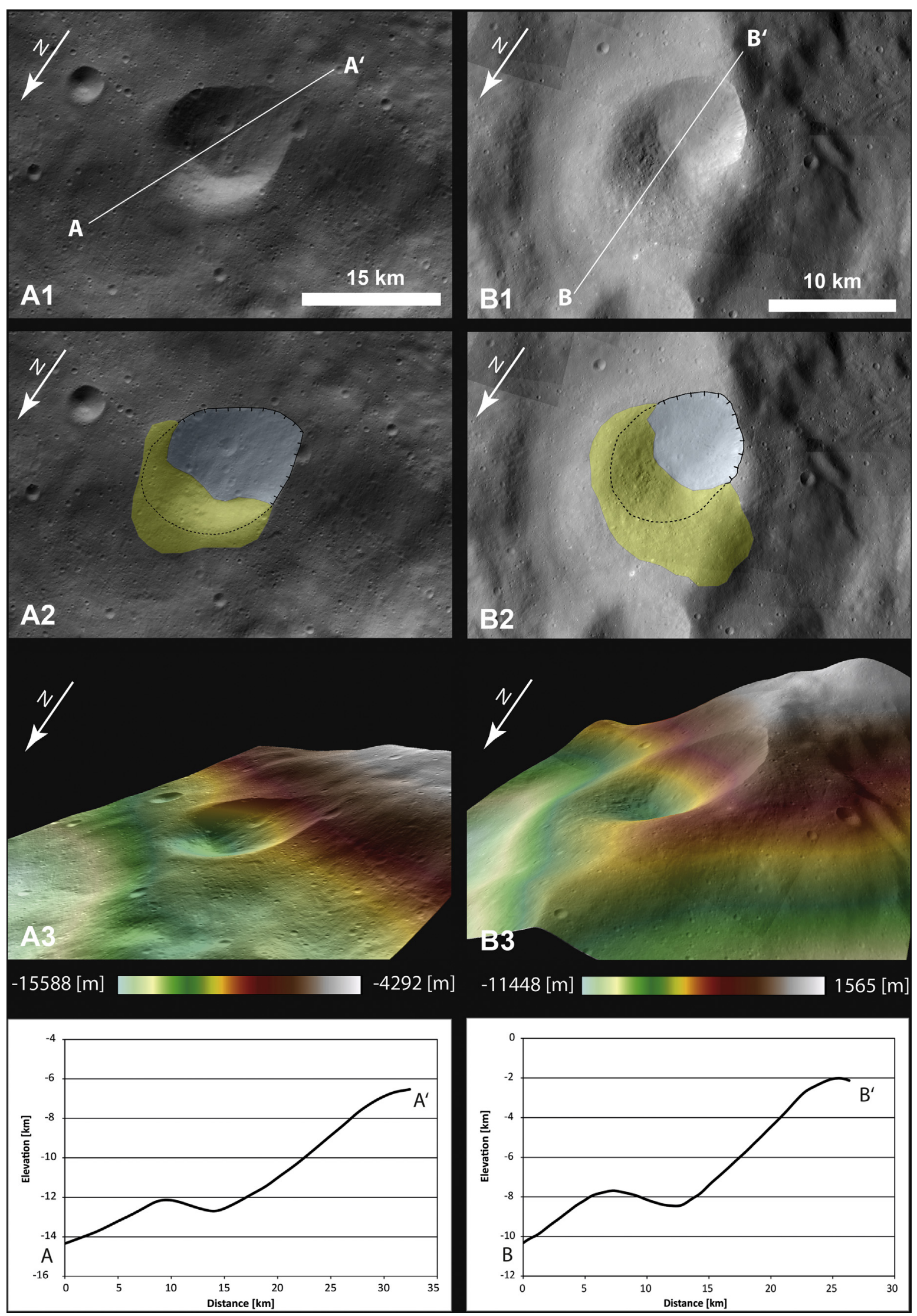

Fig. 3. Type B: Oblique elongated craters. The ejecta is distributed only on the downhill rim. (A1) LAMO FC image of an unnamed crater at $\sim$ lat $6^{\circ} \mathrm{S}$, long $299^{\circ} \mathrm{E}$. (B1) LAMO FC image of an unnamed crater at $\sim$ lat $56^{\circ} \mathrm{S}$, long $300^{\circ} \mathrm{E}$; For $(\mathrm{A} 2, \mathrm{~B} 2)$ and $(\mathrm{A} 3, \mathrm{~B} 3)$ see comments in caption of Fig. 2. 


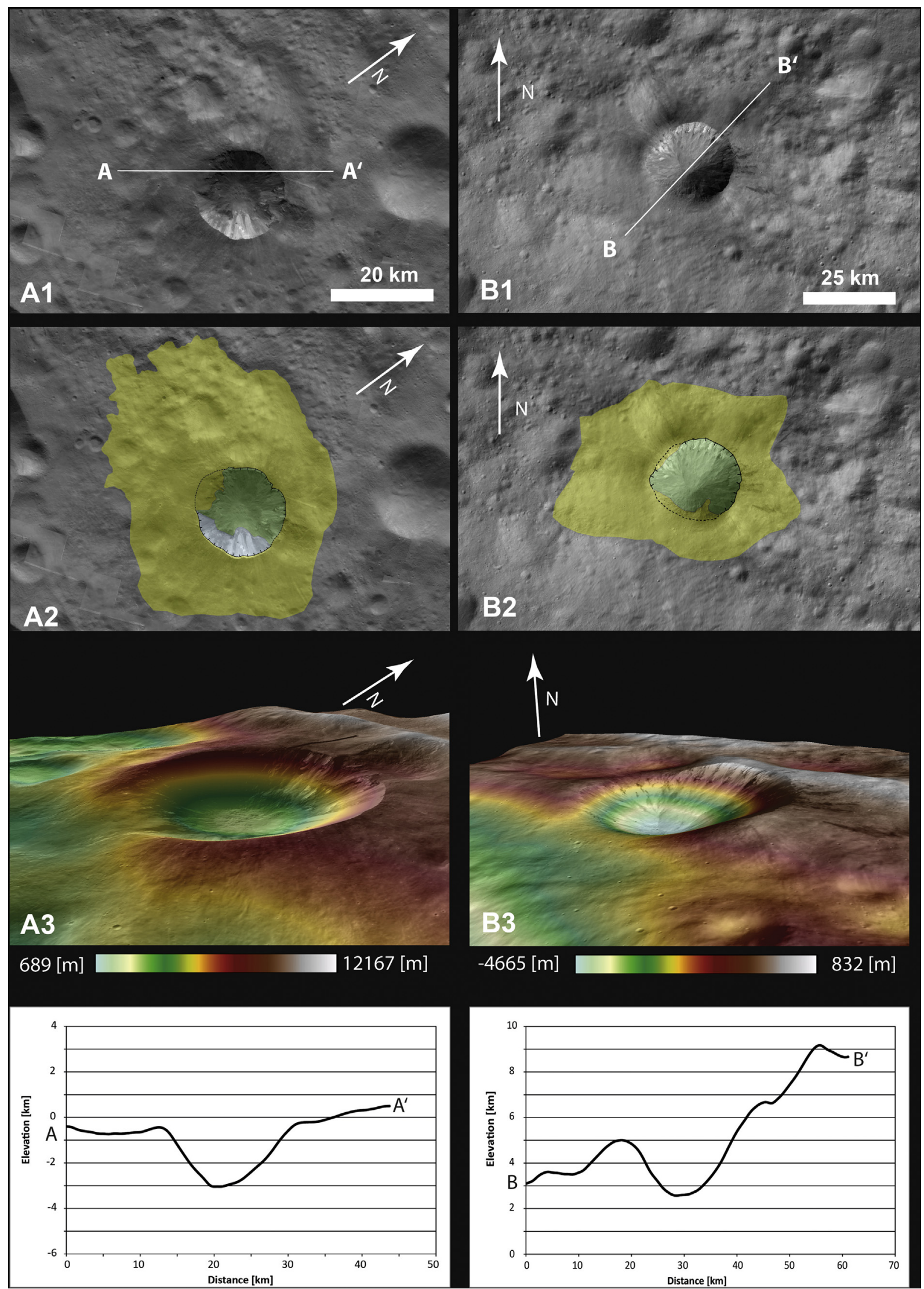

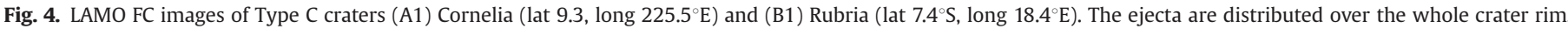

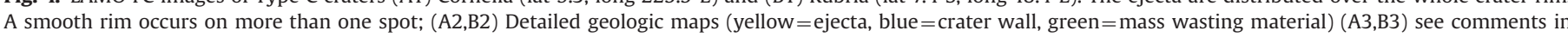
caption of Fig. 2. 


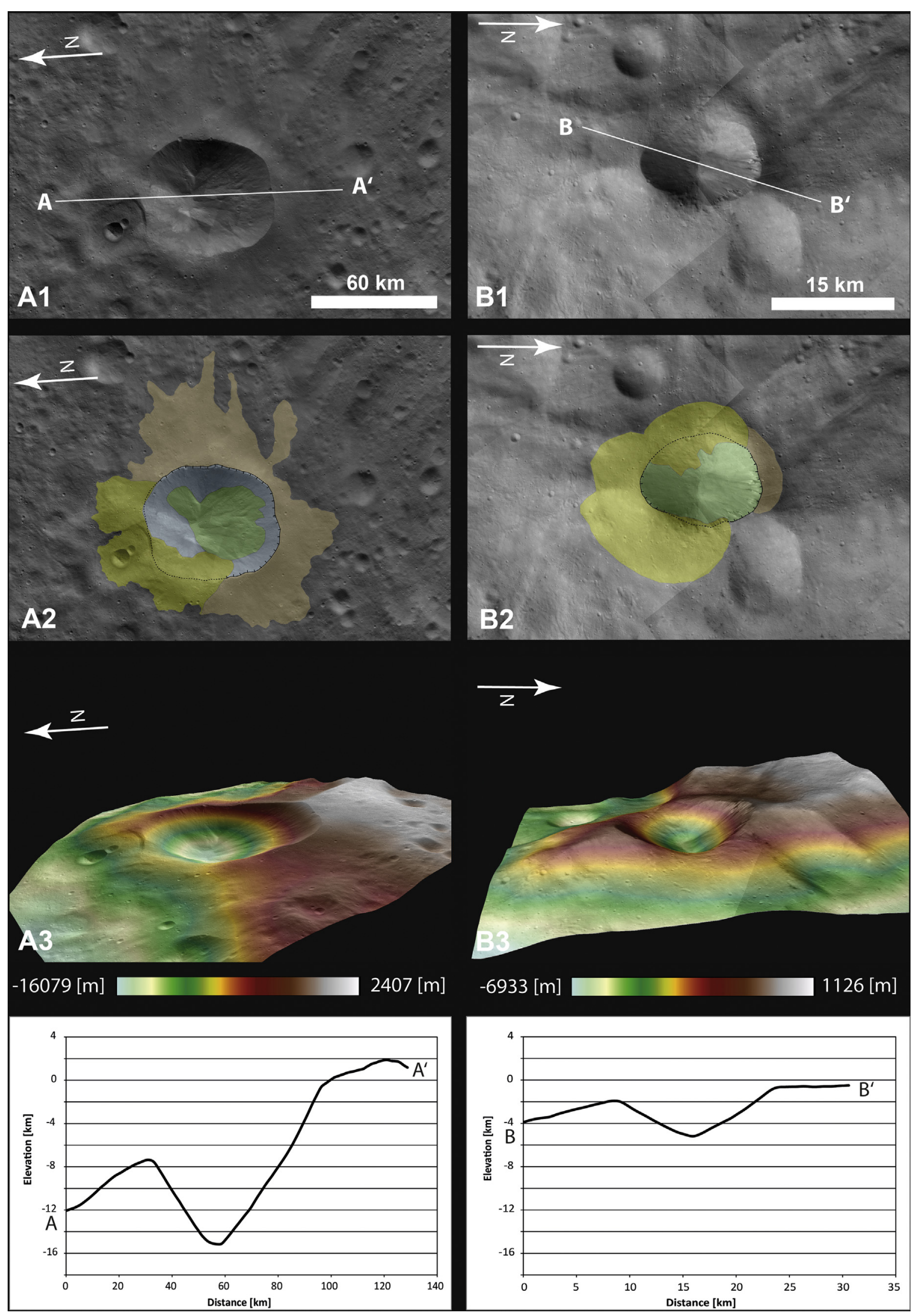

Fig. 5. V-shaped craters of Type D with a smooth downhill rim. Most ejecta is found over the downhill rim, but little ejecta are found over the uphill rim. LAMO FC images of (A1) Oppia (lat $8^{\circ} \mathrm{S}$, long $\left.309^{\circ} \mathrm{E}\right)$ and of $(\mathrm{B} 1)$ an unnamed crater $\left(\sim\right.$ lat $48^{\circ} \mathrm{S}$, long $\left.129^{\circ} \mathrm{E}\right)$. (A2, B2) Detailed geologic maps (yellow $=$ downhill ejecta, brown $=$ uphill ejecta, green $=$ mass wasting material, blue $=$ crater wall $)(\mathrm{A} 3, \mathrm{~B} 3)$ see comments in caption of Fig. 2. 

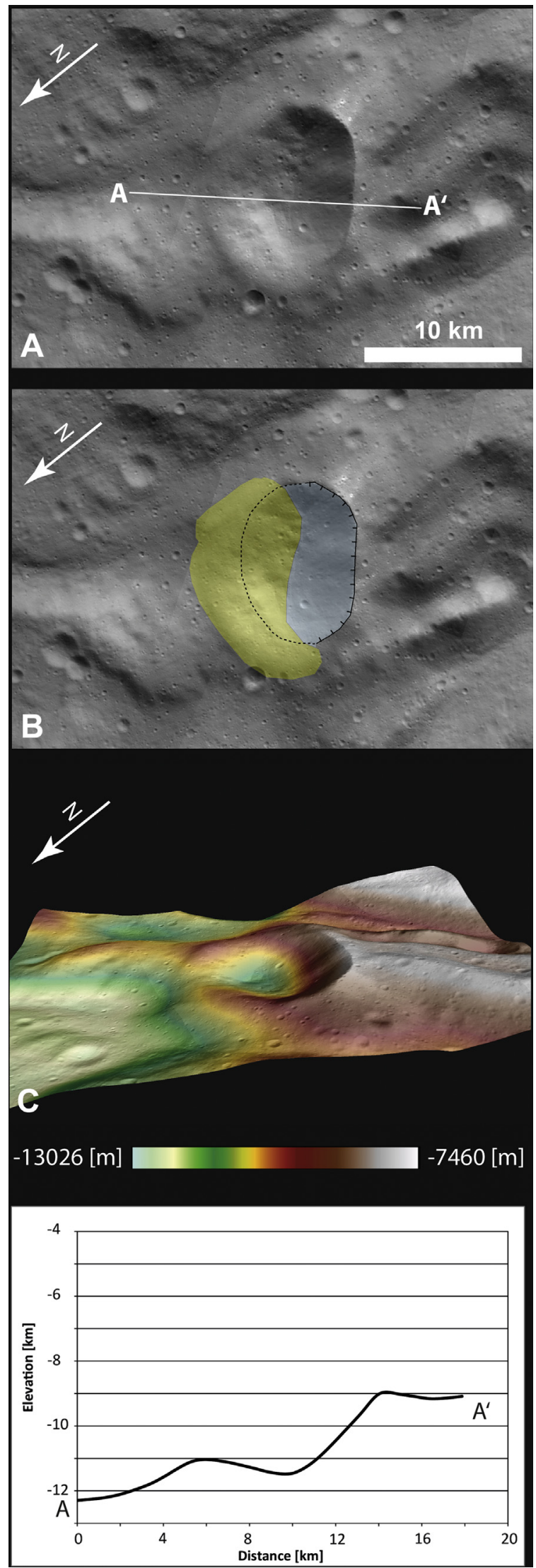

Fig. 6. (A) Lateral elongated unnamed crater of Type E with a downhill ejecta distribution ( $\sim$ lat $50^{\circ} \mathrm{S}$, long $266^{\circ} \mathrm{E}$ ) (LAMO FC image). For (B) and (C) see comments in caption of Fig. 2 .

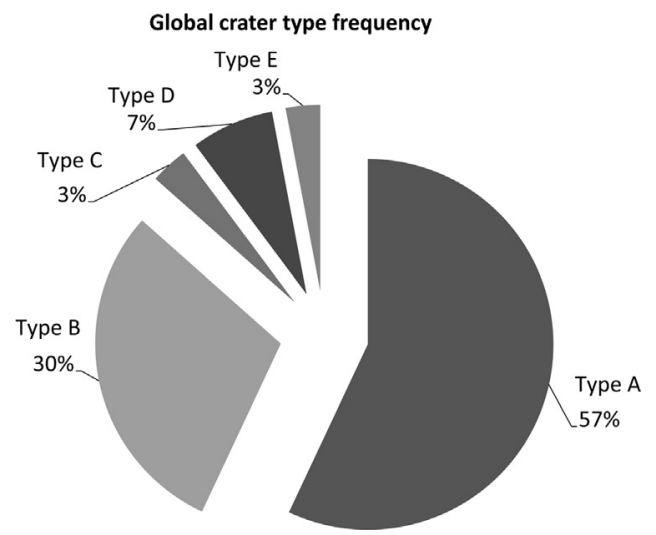

Fig. 7. Percentage distribution of all asymmetric crater types on Vesta.

differences contribute to disagreements in the surface model ages, even for ages $<3.5 \mathrm{Ga}$. For example, given the same chronology and the same crater size-frequency measurement, the difference between the crater production functions (lunar-like by Schmedemann et al. (this issue) in review) and the model production function (MPF) by Marchi et al. (2012b)) does cause a factor of two differences in the surface model ages for the floor of the Rheasilvia basin.

Furthermore, potential lunar chronology models have been reassessed recently and compared with the Neukum et al. (1994) model. The chronology model established by Marchi et al. (2009) agrees well with the model by Neukum et al. (1994), at least for ages older than $3.5 \mathrm{Ga}$. Additionally, Morbidelli et al. (2012) report a good agreement between their recently introduced so-called lunar saw tooth chronology model and the classic Neukum et al. (1994) chronology model from the present time back to $\sim 4.1 \mathrm{Ga}$.

\section{Asymmetric craters on Vesta - geomorphologic investigation and classification}

The majority of impact craters are more or less symmetrical and circular in shape. They display a classical circular bowl-shaped form with crater rims on the same elevation level at every azimuth and approximately parabolic interior profiles. However, we found 2892 craters on Vesta that deviate from this common shape. This observation suggests that these impact craters have been formed on slopes. A comparison of the distribution of craters and slopes in Section 4 will reveal whether this holds true for every crater.

In this section, we describe the morphology of these craters and present an attempt to classify them.

All of these craters show an asymmetric interior morphology and ejecta distribution. They are characterized by a well-formed, semi-circular sharp rim on the uphill side and a smooth rim on the downhill side. Local accumulation of material covers the downhill crater rim. In general ejected material on the uphill rim is only sporadically detected in thin layers. DTMs and profiles of the craters reveal mostly steep slopes uphill $\left(\sim 23-30^{\circ}\right)$ and shallower ones downhill $\left(\sim 7-16^{\circ}\right)$. Mass wasting indicators are observed on the upslope interior crater walls of many of the craters.

The craters show several commonalities but also some morphological variations. In the following, we classify them into five morphologic types, give an example of the shape of each type and attempt to illustrate the differences. However, note that the different types of craters do not necessarily imply a completely different crater formation process. 
Type A:

The general expression of asymmetric craters is displayed at the craters Antonia (lat $59.9^{\circ} \mathrm{S}$, long $200.8^{\circ} \mathrm{E}$ ) and Helena (lat $41.4^{\circ} \mathrm{S}$, long $122.5^{\circ} \mathrm{E}$ ) (Fig. 2). They have relatively steep slope angles of $24^{\circ}$ to $28^{\circ}$ on average on the uphill side, and a shallower one of about $13^{\circ}$ to $16^{\circ}$ on average on the downhill side. Most of these craters show a straight line through the crater floor that separates the oblique side from the shallower side. The uphill inner crater wall is smooth and shows a significant downhill movement of material, which meets the downhill crater rim material at the straight line (Fig. 2.). Generally, the separation line is located in the lower third of the crater. Only a narrow part of the crater floor is observable. Minor ejecta are found on the uphill rim, and the material on the downhill side is diffusely distributed over the crater and crater rim area (Fig. 2A2, B2). The majority of Type A impacted in the middle of a slope in a terrain relief of $\sim 10 \mathrm{~km}$. We have found 1712 craters of this type on the surface of Vesta.

Type B:

Type B craters show an elongated shape (Fig. 3). The rim of type $B$ is more elongated in the uphill direction than all of the other types. The downhill crater rim is less elevated than in type A, but shows similar ejecta and downhill material distribution. In some cases, the uphill rim coalesces with the slope. They have a wider crater floor, which merges into the downhill slope with a reduced crater rim. The profiles are nearly linear; therefore, the wide crater floor is clearly defined. A straight line between the crater flanks and mass wasting features is observable (Fig. 3 A2, B2). The average uphill slope is $23^{\circ}$ to $31^{\circ}$, and the average downhill slope is $7^{\circ}$ to $8^{\circ}$. The majority of Type B impacted into

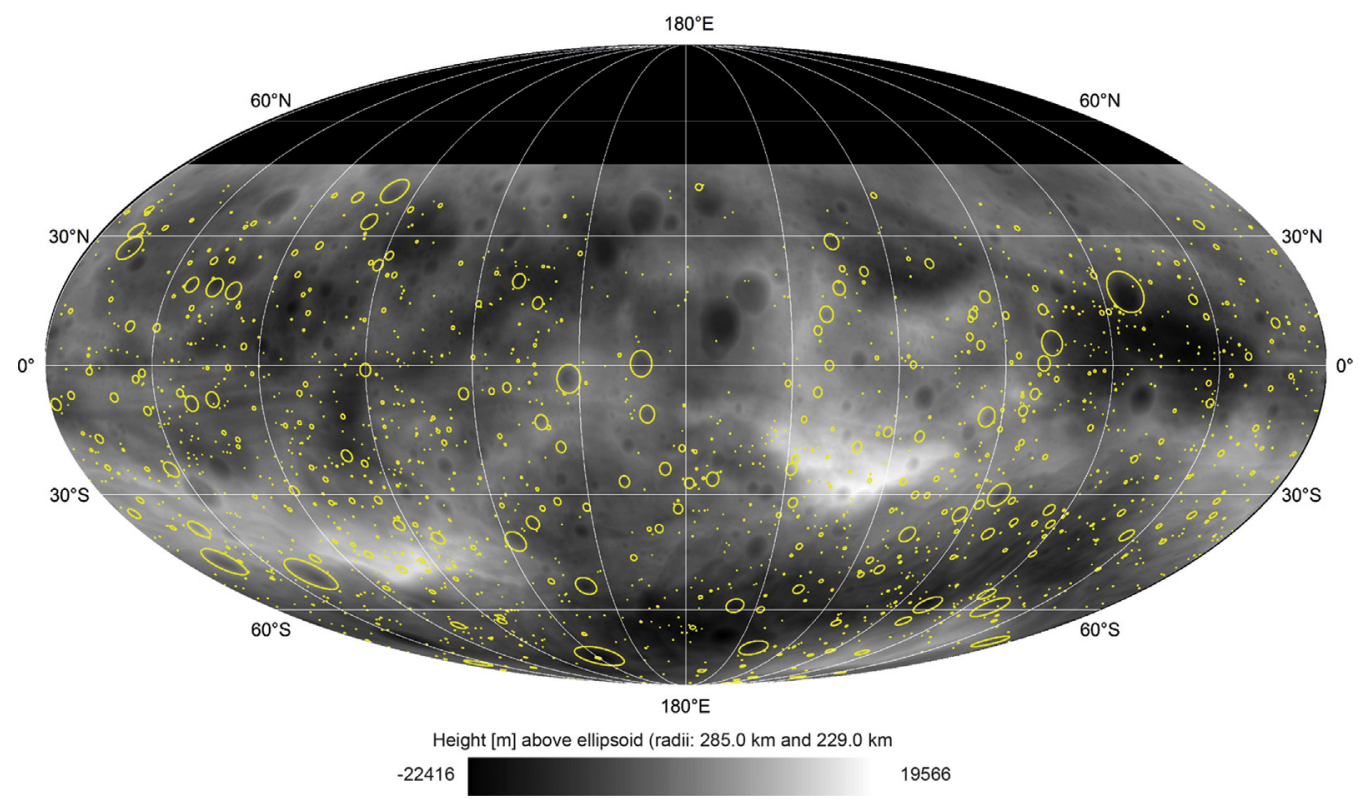

Fig. 8. Global distribution of Type A on a slope map. Type A is distributed all over Vesta. Around the region at lat $10^{\circ} \mathrm{N}$ and long $190^{\circ} \mathrm{E}$ only small asymmetric craters were formed,

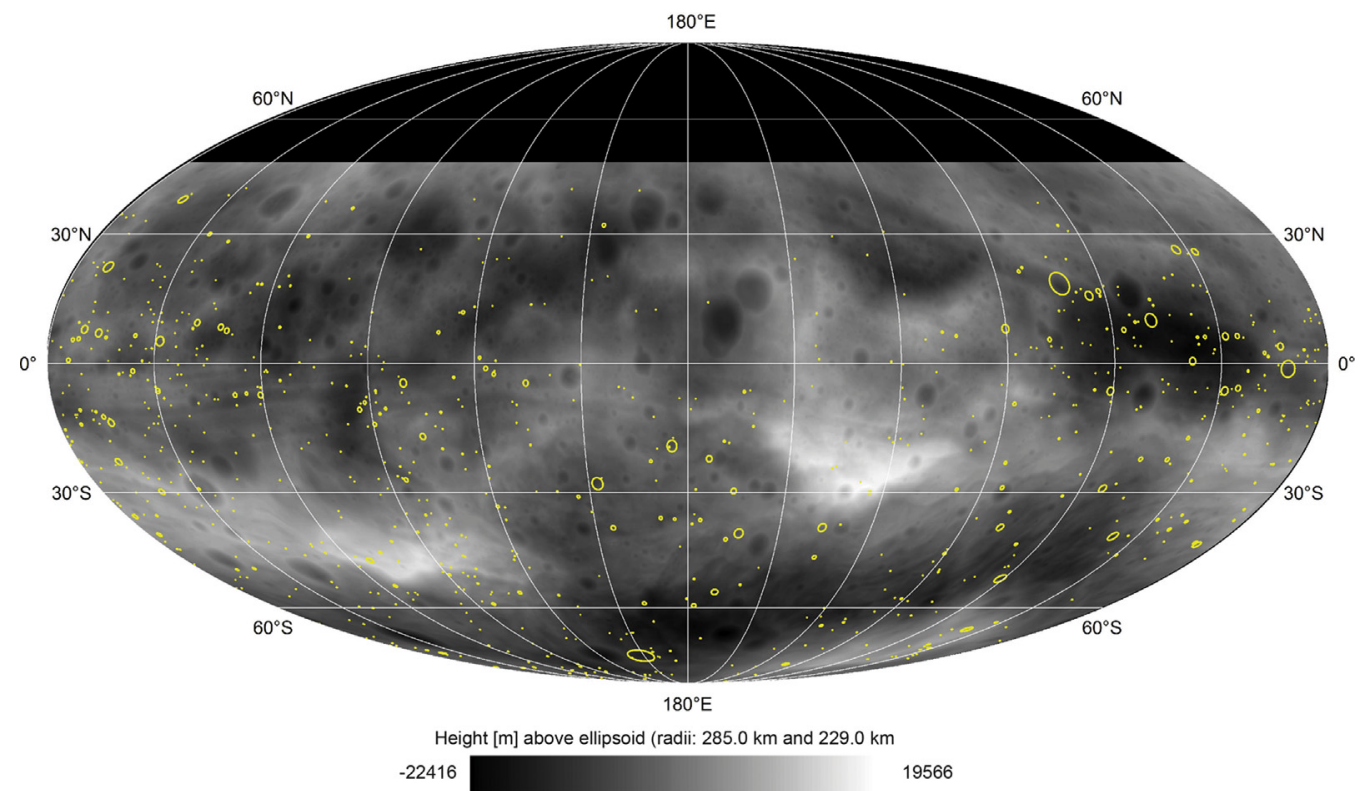

Fig. 9. Global distribution of Type B on a slope map. Type B is distributed all over Vesta. Around the region at lat $10^{\circ} \mathrm{N}$ and long $190^{\circ} \mathrm{E}$ and at around lat $0.8^{\circ} \mathrm{S}$ and long $285^{\circ} \mathrm{N}$ only a few small asymmetric craters occur, 
a $\sim 6 \mathrm{~km}$ terrain relief in the middle of the slope. We have found 799 craters of this type.

Type C:

Cornelia (lat 9.3, long $225.5^{\circ} \mathrm{E}$ ) and Rubria (lat $7.4^{\circ} \mathrm{S}$, long $18.4^{\circ} \mathrm{E}$ ) display another type of asymmetric craters (Fig. 4). They have sharp uphill rims and, compared to the common type A, have less distinctive smooth downhill rims. In contrast to the other types, ejecta are found all over the rim, but especially on the downhill side. In most cases, thin ejecta cover the sharp rim in more than one spot. Only thin layers of material cover the smooth rims. The craters exhibit no straight boundaries through the crater floor. Mass wasting material is present on all crater walls, as are boulders. The crater floor is bowl-shaped and the crater walls have nearly the same slope angle of $16^{\circ}$ on average. Type C impacted into $\sim 1.5-3 \mathrm{~km}$ terrain relief at the crest of a slope. We have found 93 craters of this type on Vesta's surface.

Type D:

Some profiles of craters, such as Oppia (lat $8^{\circ} \mathrm{S}$, long $309^{\circ} \mathrm{E}$ ) show a V-shaped crater profile with one extended wall (Fig. 5A). In this case, one crater wall is less steep than the other. However, in other cases, both crater walls have almost the same slope angle of $25^{\circ}$ on average (Fig. 5C). Those craters reveal a straight cut between the walls. The crater walls, especially the upslope crater wall, contain a lot of mass wasting material. Small amounts of ejecta are found over the uphill rim (Fig. 5A2, B2). The smooth downhill crater rim is not parallel to the straight cut, but is perpendicularly displaced. Some cases reveal two smooth crater rims opposite of each other. Mass wasting material is observable on all crater walls. The projectile

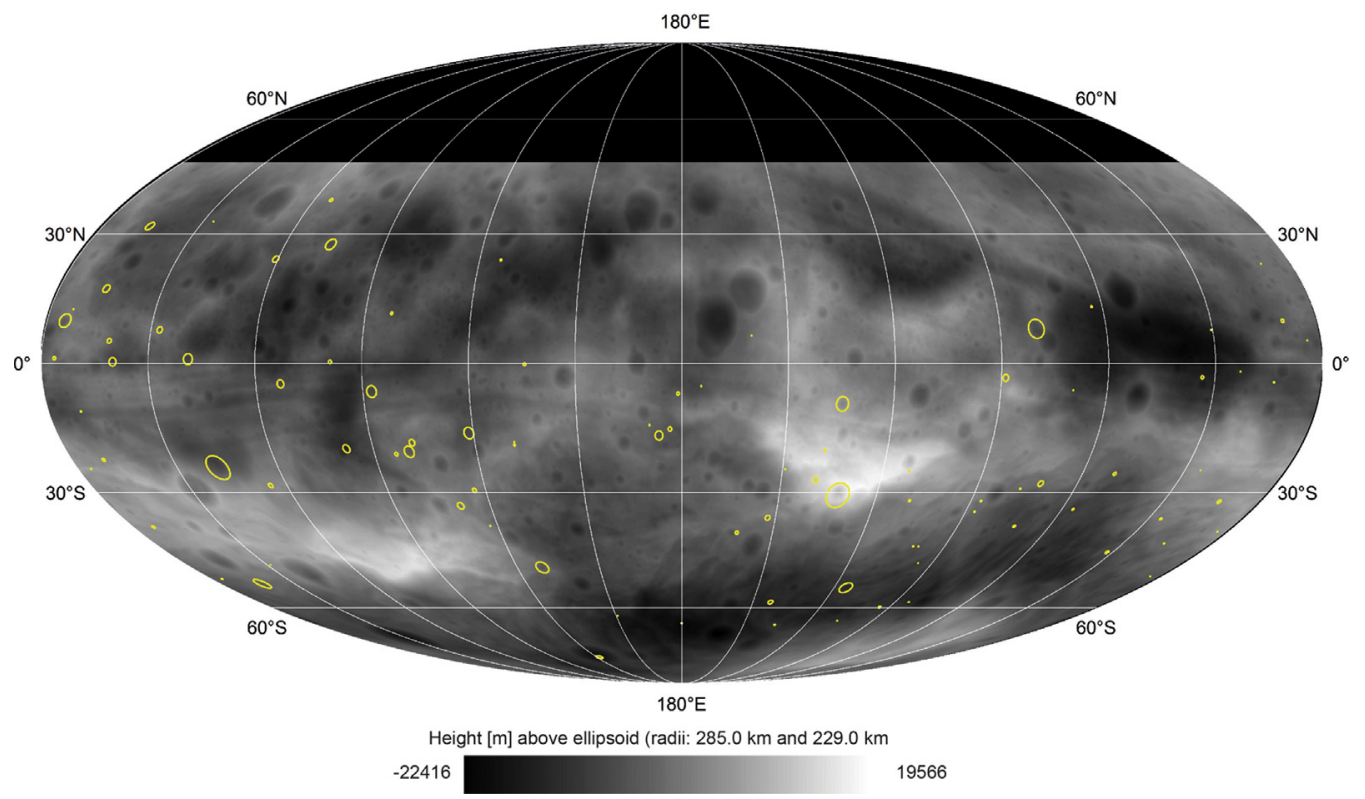

Fig. 10. Global distribution of Type $C$ craters on a slope map. Type $C$ is sporadically distributed all over Vesta.

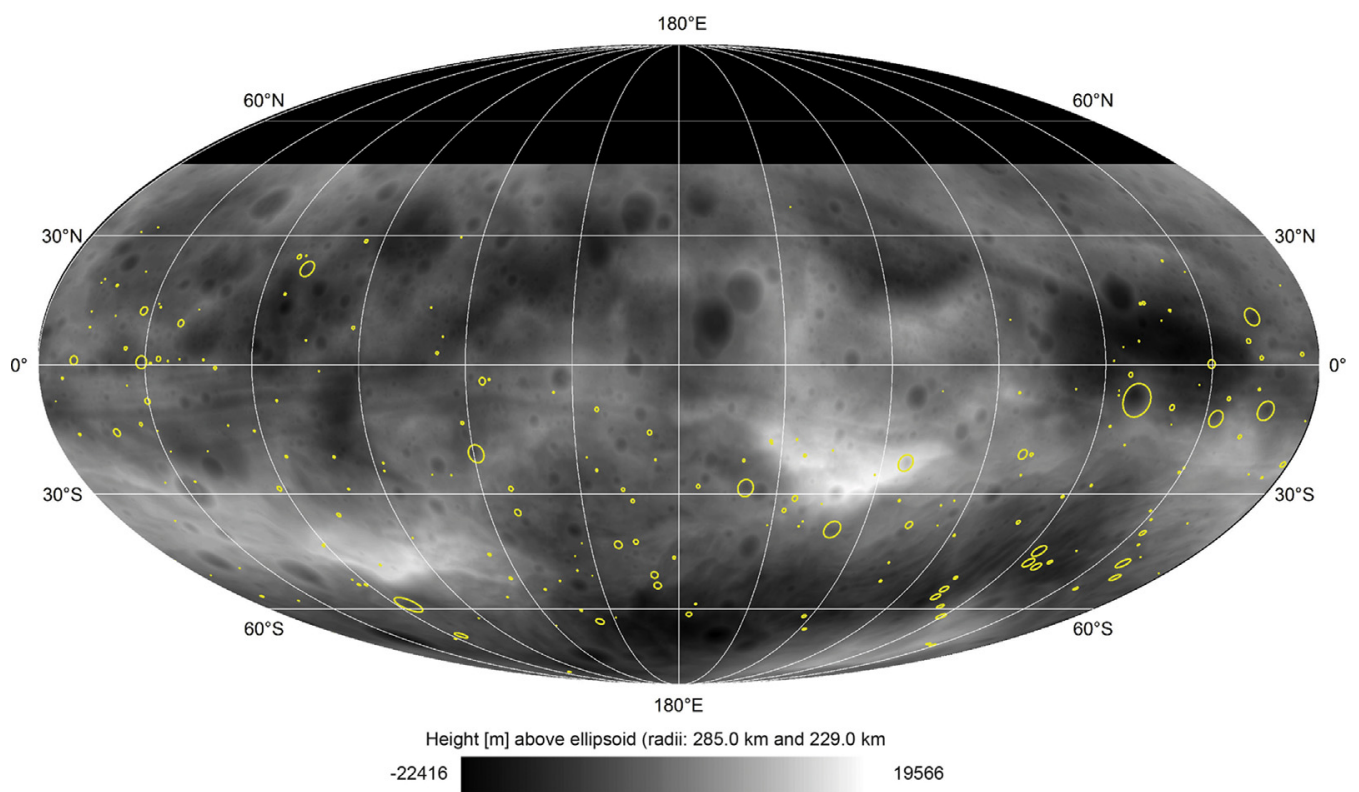

Fig. 11. Global distribution of Type D craters on a slope map. Type D is sporadically distributed all over Vesta. 
seems to have impacted on the slope crest. We have found 205 craters of this type on the surface of Vesta.

Type E:

Type E craters are those with a lateral elongated form (Fig. 6). The uphill slope is $32^{\circ}$ on average and the downhill slope is $7^{\circ}$ on average. The interior crater walls reveal less mass wasting features than the other types. The craters have a smooth downhill rim and a sharp uphill rim. This type is found, e.g. at lat $50^{\circ} \mathrm{S}$ and long $266^{\circ} \mathrm{E}$. Type E impacted into a $\sim 3 \mathrm{~km}$ terrain relief near the slope crest. We have found 83 craters of this type on Vesta's surface.

\subsection{Statistical analysis}

Asymmetric craters are distributed all over Vesta. We identified 2893 asymmetric craters on Vesta with diameters ranging from $0.3 \mathrm{~km}$ to $42.6 \mathrm{~km}$. The most common type is Type A (57\%), followed by Type B (30\%), Type D (7\%) and Type C and E (each 3\%) (see Fig. 7).

Figs. 8-12 show the distribution of the particular crater types on a DTM. Type A is distributed all over Vesta at all crater sizes. Except around the young Marcia crater region at lat $10^{\circ} \mathrm{N}$ and long $190^{\circ} \mathrm{E}$ (formation age $\sim 60-150 \mathrm{Ma}$ (Williams et al., in press)) only small asymmetric craters were formed, likely after the Marcia impact (Fig. 8).

Type B is also distributed all over Vesta with two exceptions: the Marcia region, as well as the Vestalia Terra region, a plateau located around lat $0.8^{\circ} \mathrm{S}$ and long $285^{\circ} \mathrm{E}$. In these two regions only few and small craters occur (Fig. 9).

Furthermore, there is no significant distribution trend for Type C, D and E visible in Figs. 10-12.

For our statistical analysis we grouped the craters depending on their surface slope angles. Slopes are binned in ranges from 0 to $5^{\circ}, 5$ to $10^{\circ}, 10$ to $20^{\circ}$ and $>20^{\circ}$. Figs. 13 and 14 show the number of craters of Type A and B with respect to the different slope angles. Most craters were formed on slope angles $>10^{\circ}$ with a steady decrement to lower slope angles. Fig. 14 displays the number of craters of Type C-E on different slope angles. This diagram also shows that most craters were formed on slope angles $>10^{\circ}$ with a steady decrement to lower slope angles. But it also shows that there are no craters on slope angles $<5^{\circ}$.

For our diameter to slope statistics we excluded craters with diameters $\geq 16 \mathrm{~km}$ because they obliterate the slope significantly. It is therefore not possible to determine the exact surface slope angle for crater diameters $\geq 16 \mathrm{~km}$. At the other end craters with a diameter $<0.3 \mathrm{~km}$ are hardly identifiable on the images. Thus we focused mainly on craters with diameters ranging from $0.3 \mathrm{~km}$ to $16 \mathrm{~km}$.

Figs. 15 and 16 show the crater frequency over diameters in correlation with the slope angles for Type A and Type B. For diameters from $0.3 \mathrm{~km}$ to $0.7 \mathrm{~km}$ crater frequency increases strongly. The peak is reached at $0.7 \mathrm{~km}$ and then decreases continuous. We see that the larger the craters are the fewer are the number of crater on slope angles.

No clear peaks can be identified for the other three types. A statistical analysis does not show a clear distribution profile but a random distribution.

\section{Discussion}

We now consider what may be producing these asymmetric craters. Because erosion and tectonics do not play a significant role

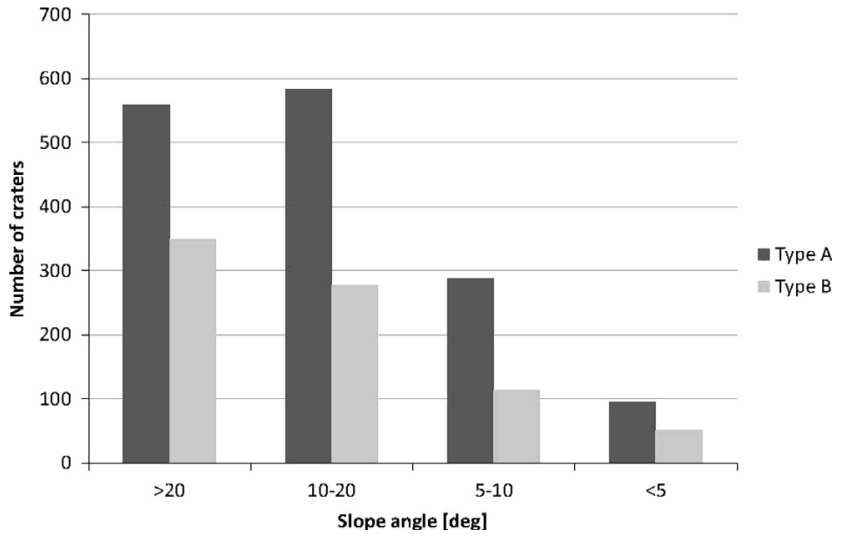

Fig. 13. This figure shows the number of Type A and B craters on the different slope angles. Most craters are formed on slope angles $>10^{\circ}$

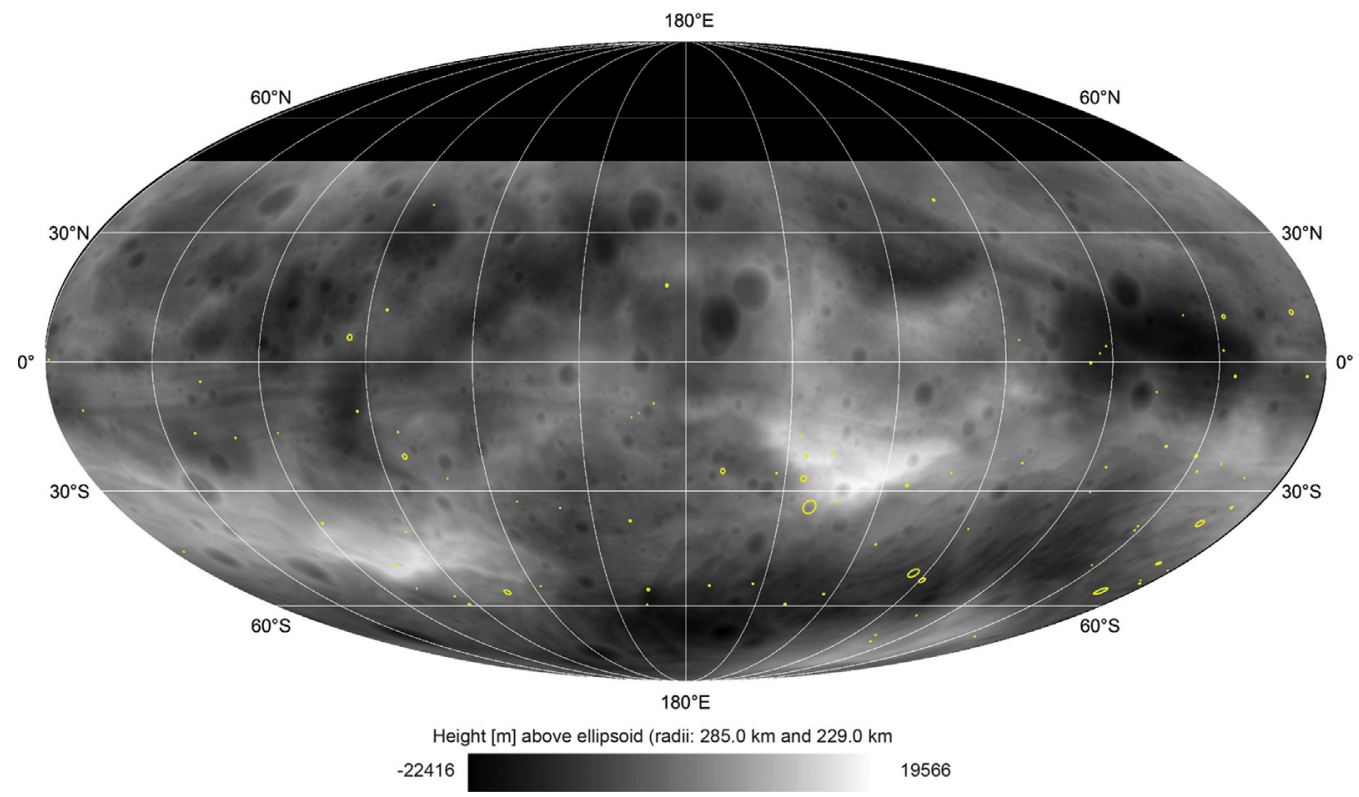

Fig. 12. Global distribution of Type E craters on a slope map. Type E is sporadically distributed all over Vesta. 


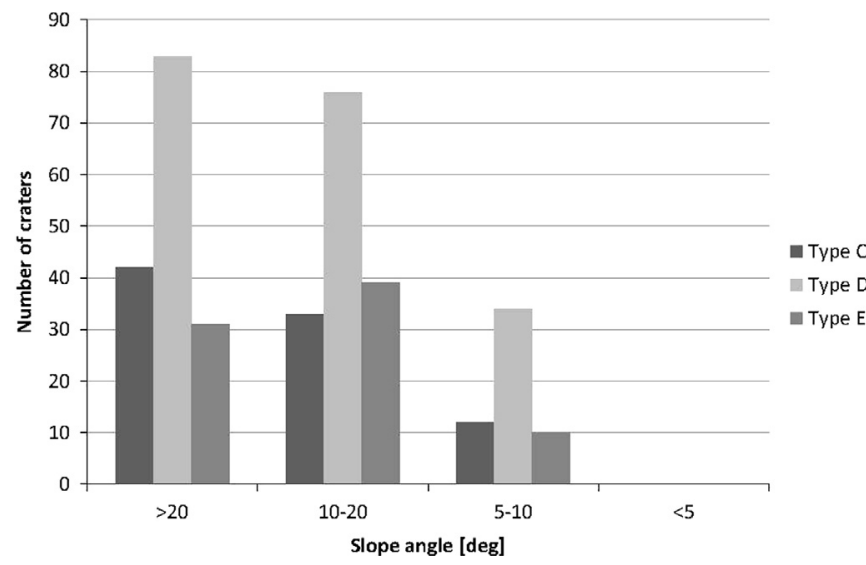

Fig. 14. This figure shows the number of Type $C$ to $E$ craters on the different slope angles. Most craters are formed on slope angles $>10^{\circ}$ and no craters on slope angles $<5^{\circ}$.

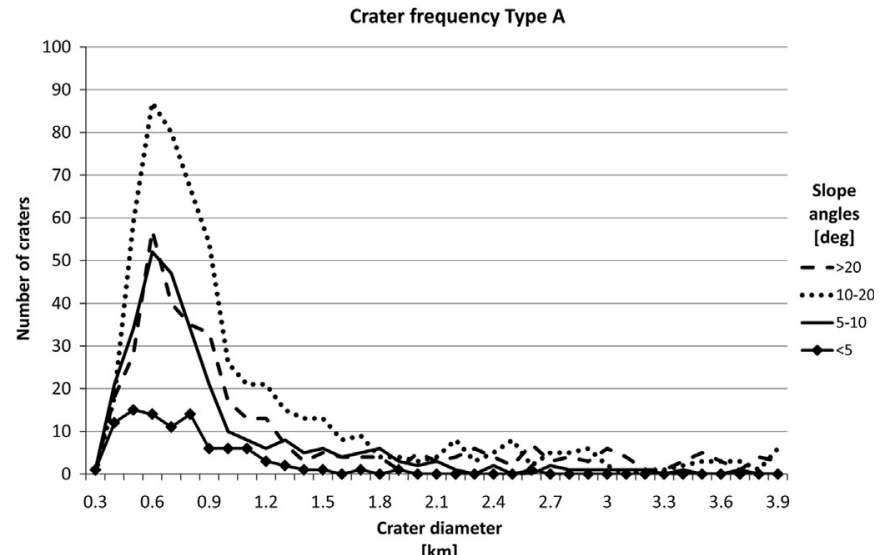

Fig. 15. Crater frequency over diameters in correlation of the slope angles for Type A. The figure shows a strong increase for diameters from $0.3 \mathrm{~km}$ to $0.7 \mathrm{~km}$ followed by a continuous decrease.

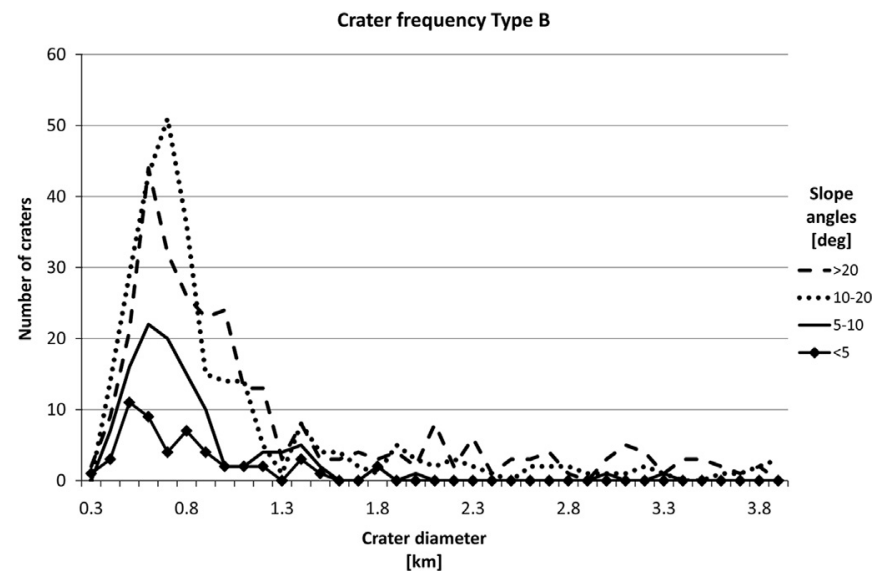

Fig. 16. Crater frequency over diameters in correlation of the slope angles for Type B. The figure shows a strong increase for diameters from $0.3 \mathrm{~km}$ to $0.7 \mathrm{~km}$ followed by a continuous decrease.

on Vesta, an oblique angle of incidence or target heterogeneities, such as topography, are the most likely causes for the asymmetries. Morphological analysis of selected craters (see previous section) and the statistical analysis suggest that these have been formed on slopes and, thus, seem to support this assumption.

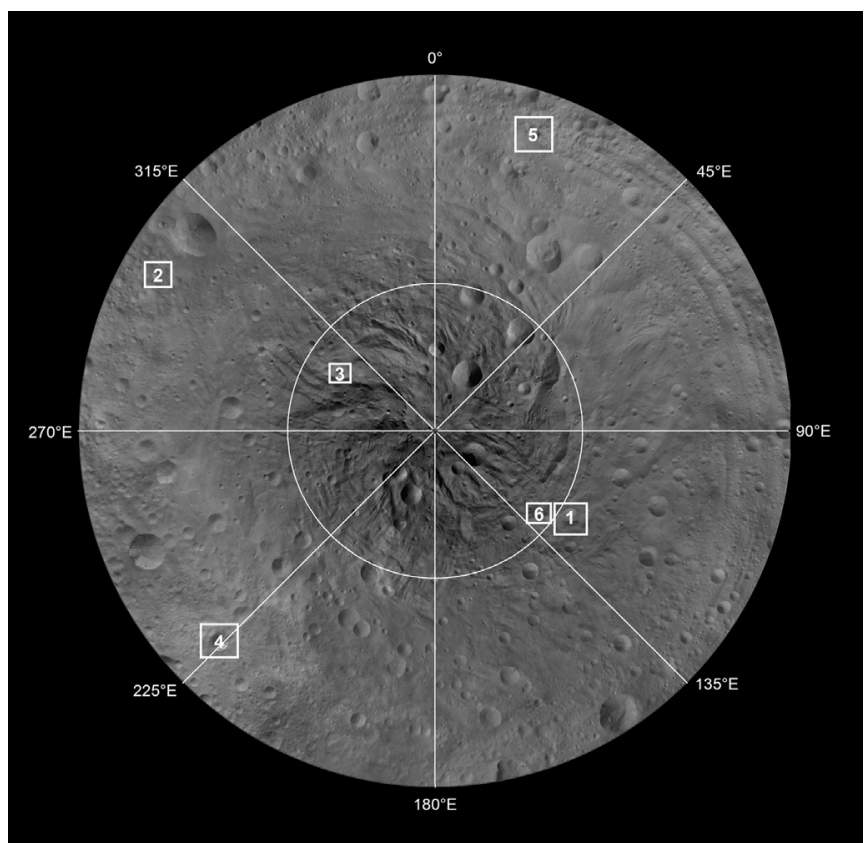

Fig. 17. Locations of the craters which were used for age determinations.

Table 2

List of age measurements of the different asymmetric crater types as shown in Figs. 18-23. $\mathrm{N}$ is the number of counted craters, $\mathrm{N}(1)$ gives the cumulative crater frequency at $1 \mathrm{~km}$ crater diameter of the production function as it is fitted to the measurement.

\begin{tabular}{|c|c|c|c|c|c|}
\hline Location & $\begin{array}{l}\text { Counting } \\
\text { area } \\
\left(\mathbf{k m}^{2}\right)\end{array}$ & $\begin{array}{l}\text { n } \\
\text { craters }\end{array}$ & $\begin{array}{l}N(1) \times \\
10^{-3}\end{array}$ & Age (Ma) & $\begin{array}{l}\text { Resurfacing } \\
\text { age }\end{array}$ \\
\hline \multicolumn{6}{|l|}{ Type A crater } \\
\hline Helena interior & 29.02 & 643 & 3.14 & $351 \pm 84$ & $154 \pm 7.6$ \\
\hline Helena NE & 57.49 & 864 & 2.44 & $317 \pm 58$ & $120 \pm 5.8$ \\
\hline Helena S & 34.22 & 835 & 2.34 & $353 \pm 43$ & $115 \pm 5.5$ \\
\hline Helena SE & 30.56 & 825 & 3.44 & $169 \pm 6.7$ & \\
\hline Helena W & 32.84 & 869 & 2.59 & $408 \pm 53$ & $127 \pm 4.9$ \\
\hline \multicolumn{6}{|l|}{ Type B crater } \\
\hline 299E $6 S-E$ & 10.05 & 125 & 6.77 & $332 \pm 46$ & \\
\hline $\begin{array}{c}\text { 299E 6S - } \\
\text { interior }\end{array}$ & 13.25 & 186 & 9.67 & $475 \pm 110$ & \\
\hline 299E 6S - N & 12.01 & 120 & 6.58 & $323 \pm 57$ & \\
\hline $300 E 56 S-E$ & 23.05 & 85 & 4.88 & $240 \pm 35$ & \\
\hline $\begin{array}{c}300 \mathrm{E} 56 \mathrm{~S}- \\
\text { interior }\end{array}$ & 25.25 & 65 & 5.49 & $270 \pm 57$ & \\
\hline $300 \mathrm{E} 56 \mathrm{~S}-\mathrm{N}$ & 24.14 & 77 & 5.08 & $249 \pm 33$ & \\
\hline \multicolumn{6}{|l|}{ Type C crater } \\
\hline Cornelia NE & 10.74 & 97 & 0.25 & $12.1 \pm 1.2$ & \\
\hline Cornelia SE & 15.98 & 114 & 0.19 & $9.36 \pm 0.91$ & \\
\hline Cornelia SW & 13.54 & 162 & 0.29 & $14.1 \pm 1.1$ & \\
\hline Cornelia W & 10.51 & 82 & 0.30 & $10.2 \pm 1.1$ & \\
\hline Rubria E & 15.63 & 436 & 0.29 & $14.1 \pm 3.9$ & \\
\hline Rubria N & 10.05 & 239 & 0.28 & $18.8 \pm 4.8$ & \\
\hline Rubria NW & 10.64 & 229 & 0.29 & $14.3 \pm 3$ & \\
\hline Rubria SE & 63.34 & 684 & 0.35 & $17 \pm 4.9$ & \\
\hline Rubria SW & 15.63 & 151 & 0.40 & $19.6 \pm 1.6$ & \\
\hline Rubria W & 19.68 & 293 & 0.47 & $23.1 \pm 1.4$ & \\
\hline \multicolumn{6}{|l|}{ Type D crater } \\
\hline $129 \mathrm{E} 48 \mathrm{~S}-\mathrm{S}$ & 22.52 & 172 & 4.60 & $226 \pm 21$ & \\
\hline $129 E 48 S-S E$ & 16.25 & 108 & 3.51 & $172 \pm 29$ & \\
\hline $\begin{array}{l}\text { 129E 48S - } \\
\text { slope }\end{array}$ & 17.29 & 85 & 1.36 & $253 \pm 67$ & \\
\hline $129 \mathrm{E} 48 \mathrm{~S}-\mathrm{W}$ & 29.23 & 159 & 3.72 & $182 \pm 20$ & \\
\hline
\end{tabular}

Furthermore we want to prove if the smooth crater rim material is a product of the impact itself or could have been formed by subsequent post-impact processes. 
The statistical analysis shows a global distribution of asymmetric craters on slopes. At all slope angles a peak at crater diameters of $0.7 \mathrm{~km}$ occurs. There is not final explanation why the peak is reached at $0.7 \mathrm{~km}$. We expected to have cumulative crater frequencies for smaller diameters. But why did not we see no smaller craters? Currently we have three possible explanations for this circumstance:

- Craters with diameters below $0.7 \mathrm{~km}$ it may be difficult to distinguish, whether they are asymmetric or not due to the ground resolution of the dawn images.

- Small craters can be covered with ejecta of other impact craters, buried by mass wasting materials or can have been removed by erosion.

- Large craters obliterate the slope significantly and eliminate them, especially the low altitude slopes.

It may also be possible that a combination of all causes this.

\subsection{Age determination}

Crater size frequency measurements were performed on ejecta blankets around the asymmetric craters as well as on downhill material and on material of the interior (e.g., floors) of a few craters. FC color images in the form of Clementine ratio maps (Isaacson and Pieters, 2009; Tompkins and Pieters, 1999) shows that ejecta deposits were emplaced around most of the craters that were counted. The age measurements were conducted to compare uphill ejecta, if existing, and downhill material to prove whether they were deposited simultaneously or if the downhill material was influenced by post-emplacement modifications.

Fig. 17 provides an overview map of the measured craters. Table 2 gives the ages of the measured crater types. The measurements of type A crater Helena (Fig. 18) show a resurfacing event possibly generated by (1) seismic shaking or (2) covering by ejecta from other impacts. The base ages of 300-400 Ma almost certainly give the formation age of Helena because the interior
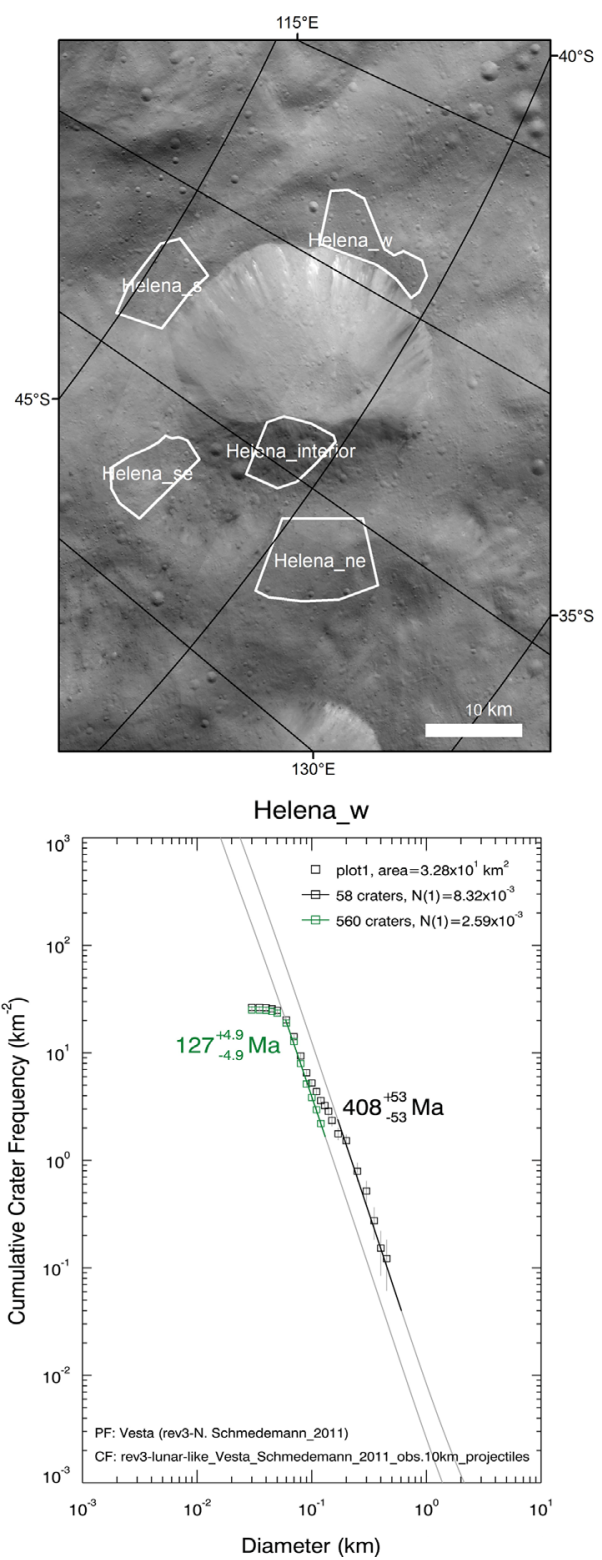
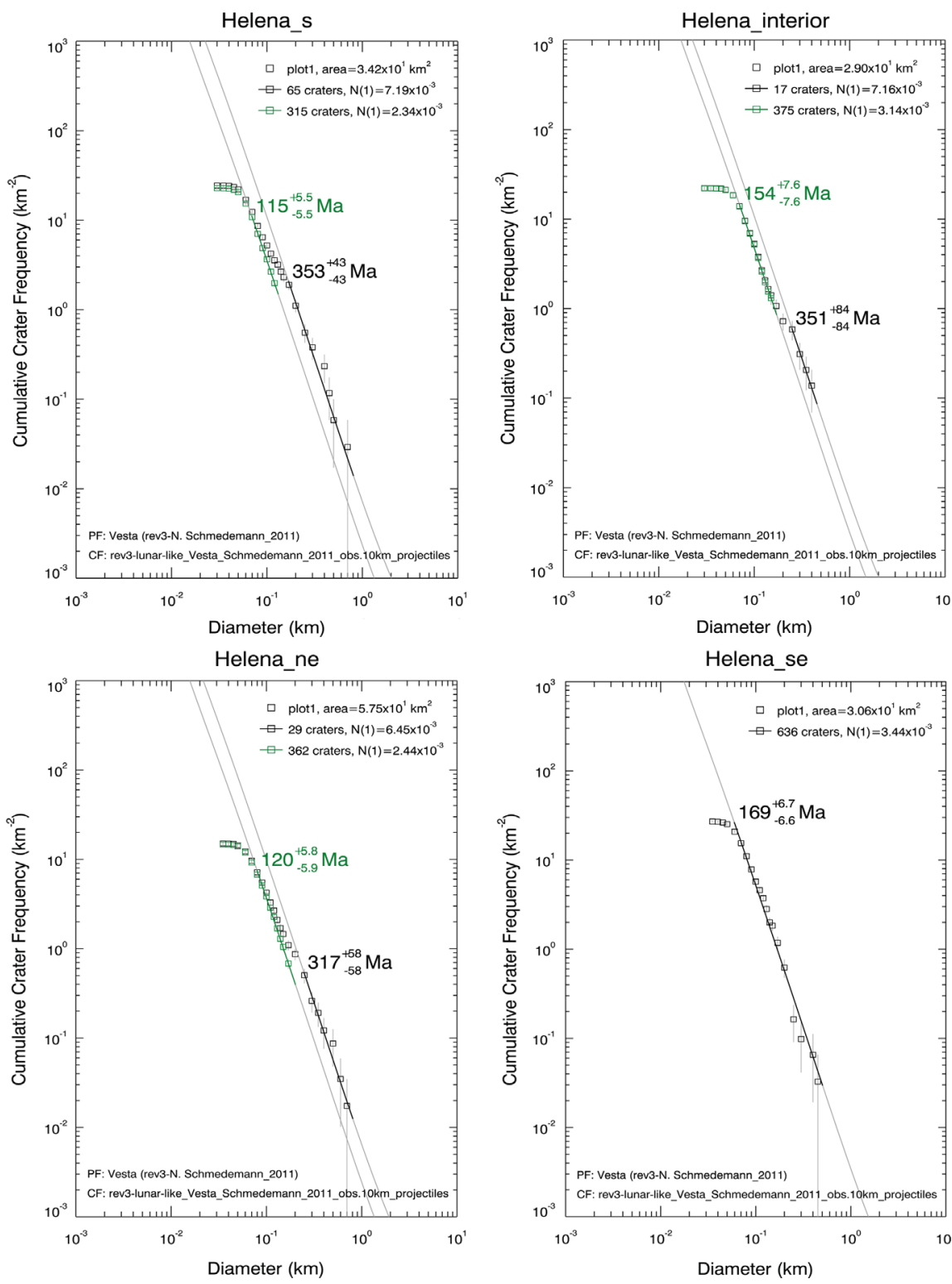

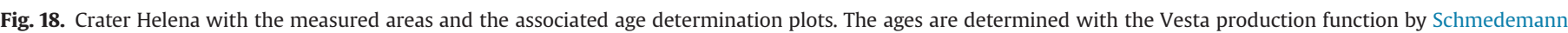
et al. (2012). See also Table 2 for measurement details. 
measurements also reveal similar age. Older craters would have been destroyed by the impact. Measurements of the ejecta of type A crater Antonia indicate a formation age of $\sim 21-25 \mathrm{Ma}$ (Kneissl et al., 2013).

The ages of the type $\mathrm{B}$ and $\mathrm{D}$ craters are in the same range as Helena, between $\sim 270$ and $475 \mathrm{Ma}$ (Fig. 19, Fig. 20, Fig. 21), as well
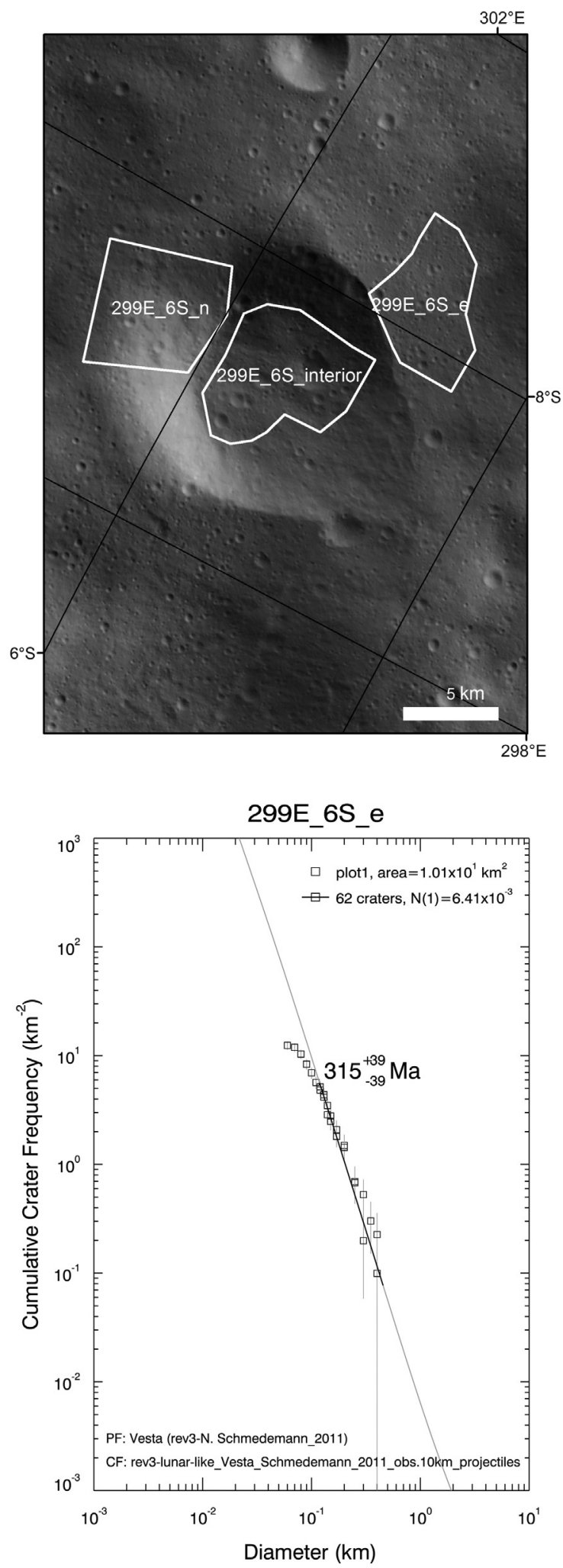

Eusebia, which is between $\sim 210 \mathrm{Ma}$ and $261 \mathrm{Ma}$ (Kneissl et al. 2013). Crater counts on the surrounding ejecta of type $C$ show that the ages of the craters Cornelia (Fig. 22) and Rubria (Fig. 23) are very young, between $\sim 9$ and $23 \mathrm{Ma}$ (see Table 2 ).

The dated craters are very young compared to the age of Vesta. A possible explanation of this phenomenon could be the fast
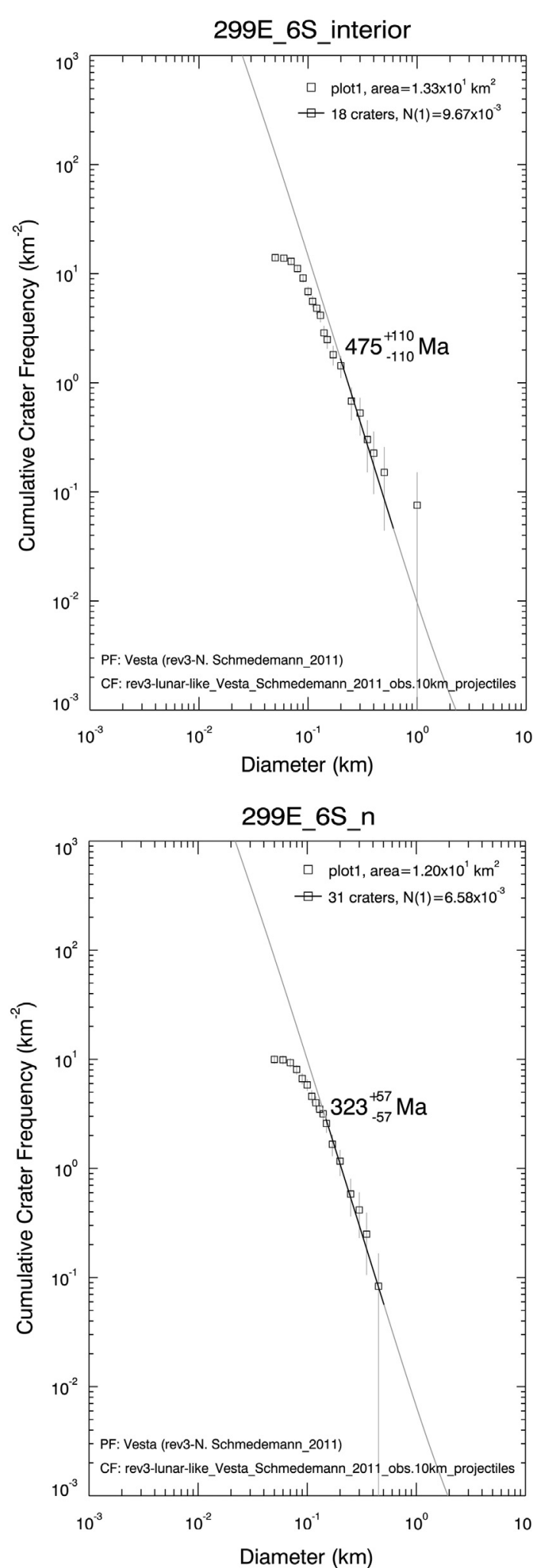

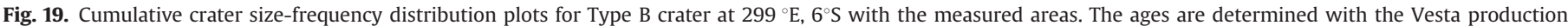
function by Schmedemann et al. (2012). See also Table 2 for measurement details. 

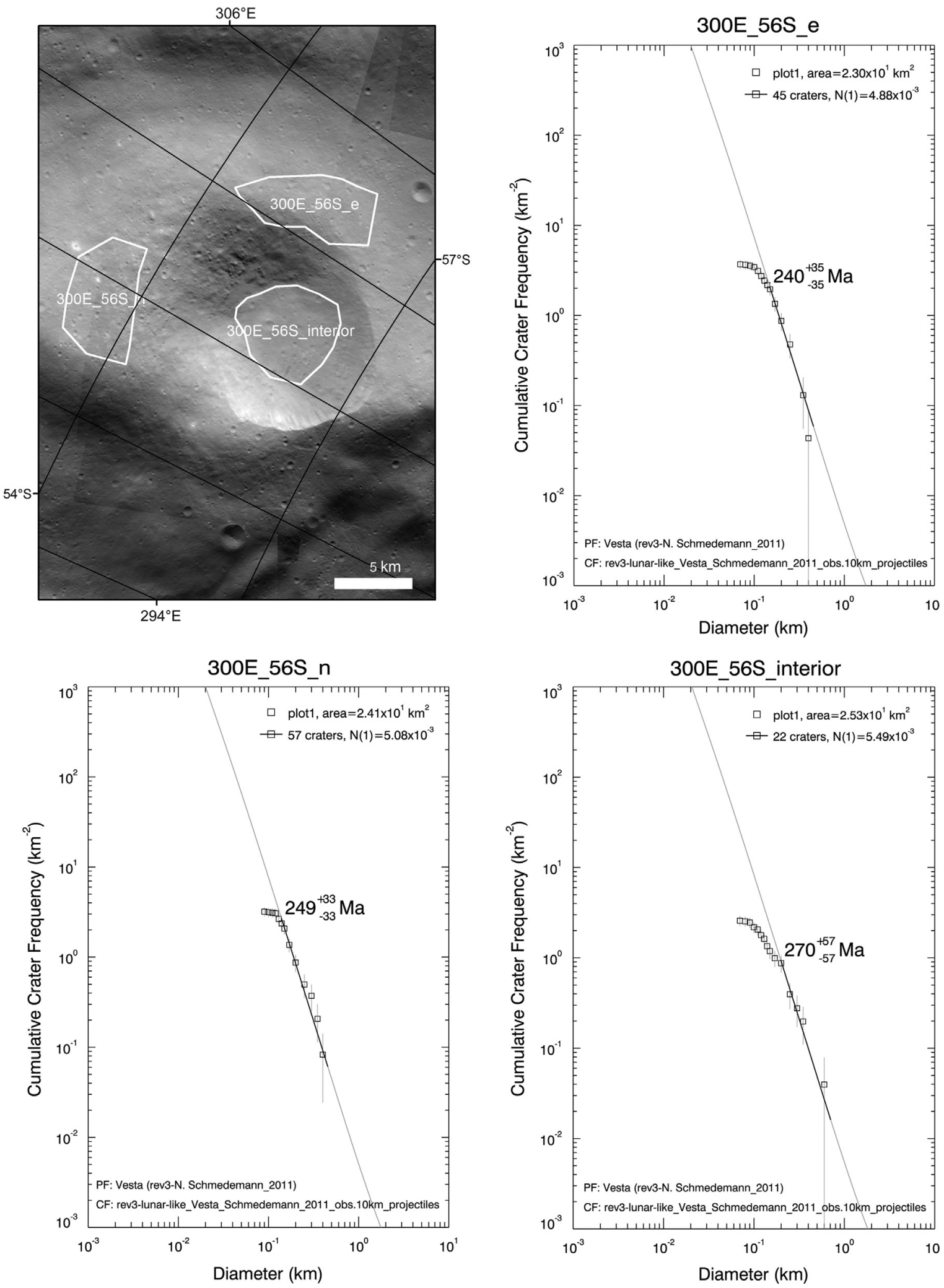

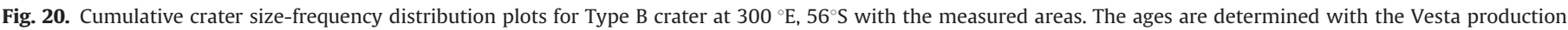
function by Schmedemann et al. (2012). See also Table 2 for measurement details.

degradation of sharp crater rims on uphill sides and, therefore, the older craters would not be defined as asymmetric craters.

The measurements on the downslope deposits and the crater interiors (as far as those that are usable for dating) fit very well with the measurements on the surrounding remaining ejecta, as shown for Helena. This means that no further modification processes other than impact affecting the superimposed crater distribution are detectable within the 

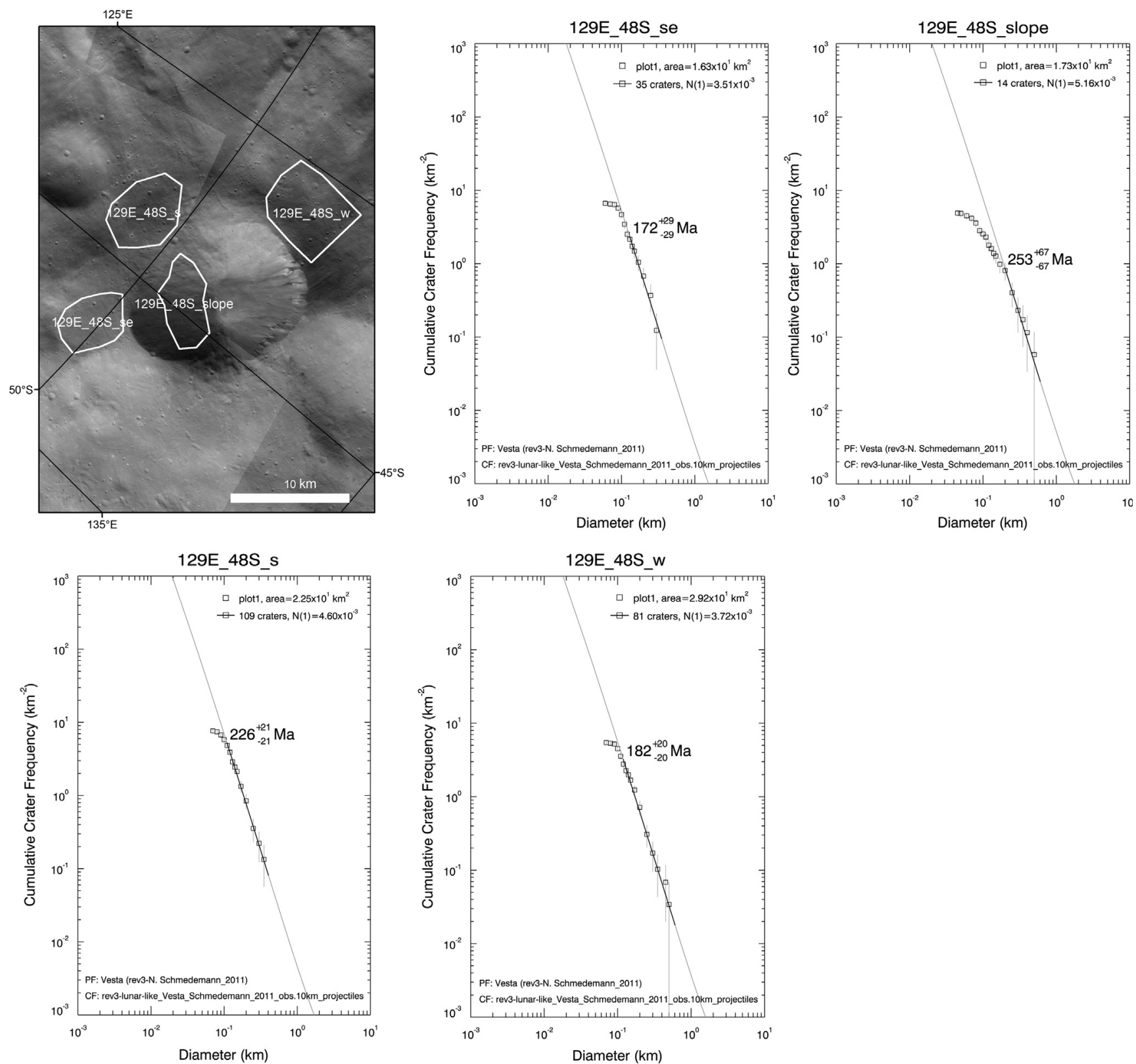

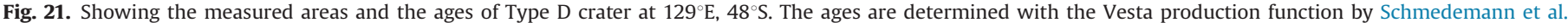
(2012). See also Table 2 for measurement details.

measurement uncertainty and within the uncertainty of the cratering chronology model.

\subsection{Numerical modeling of impacts into slopes}

We have illustrated that the occurrence of the asymmetric craters on Vesta correlates with the distribution of the slopes. This suggests that topography might be the most significant influence leading to the formation of these special types of asymmetric craters; this is further discussed in this section.

Previous studies have revealed that the shape of an impact crater, and especially its ejecta distribution, is the result of a complex interaction of the topographic conditions, an oblique angle of incidence, impact energy (i.e., size, density, and velocity of the projectile), the impact position relative to the topography, and the properties of the target material (Elbeshausen and Wünnemann, 2011). These studies also showed that the crater shape is only influenced by impacts into tilted target surfaces with an altitude difference of approximately 30\% or greater of the projectile's diameter. The distribution of ejected material is influenced by even smaller differences in elevation (Elbeshausen et al., 2012). Most of the altitude differences measured is even larger than the expected projectile sizes required to form an asymmetric crater. For the Helena impact site (see Fig. 2), e.g., the altitude difference is 1600 $1800 \mathrm{~m}$, while the projectile which formed this crater is estimated about $1 \mathrm{~km}$ in diameter. Thus, it is likely that the formation of the asymmetric craters has been influenced by the presence of slopes.

Here, we conducted numerical simulations to investigate whether it is possible that the observed asymmetries, both in the ejecta blanket and in the crater shape, might have been resulted from target topography. The main questions arising here are as follows: How does the slope affect the cratering process? Is it possible to explain the asymmetric morphology of these craters solely by the presence of topography?

Currently, there are still many unknowns of how topography affects the shape of craters and their formation - and how these 

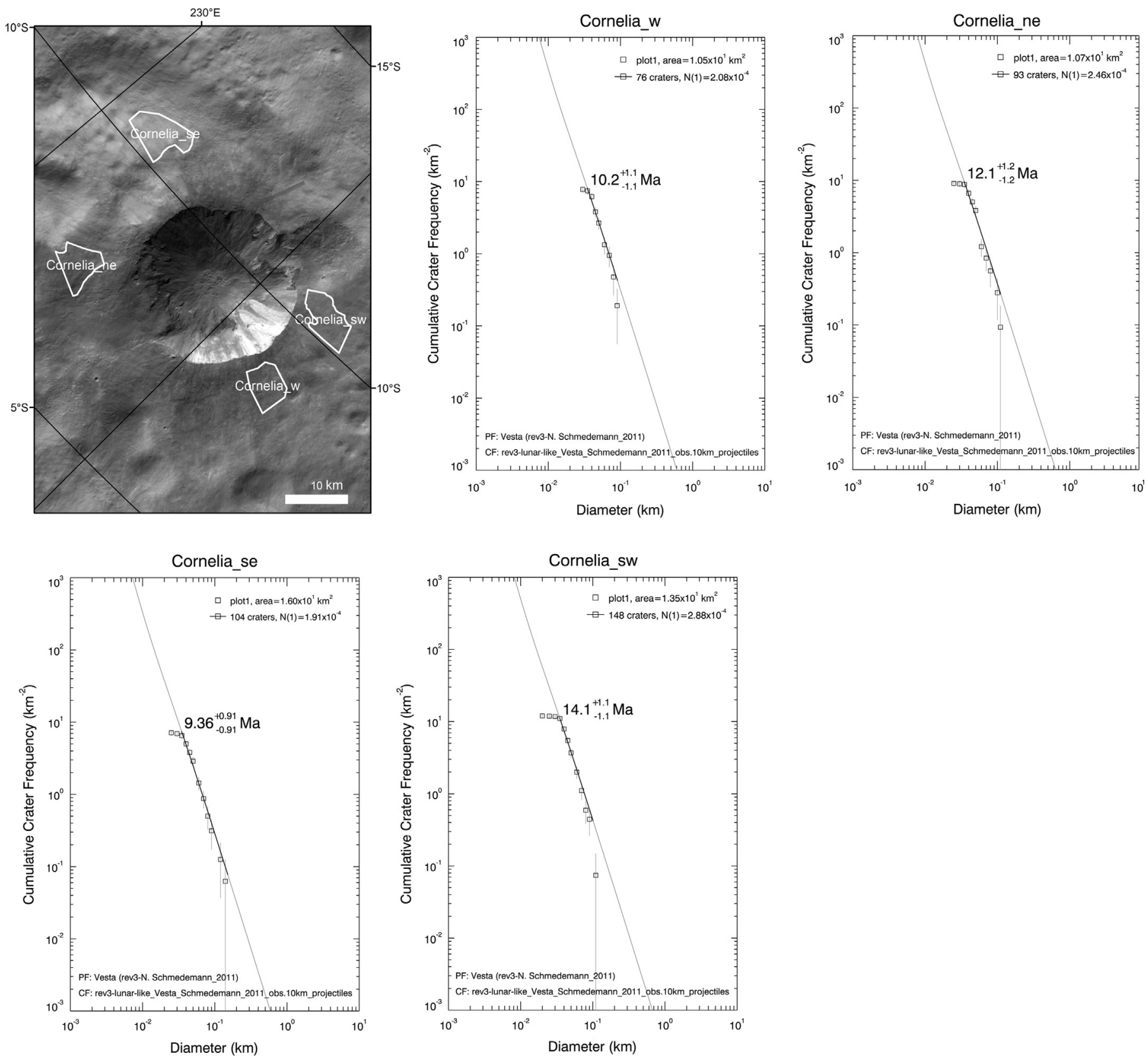

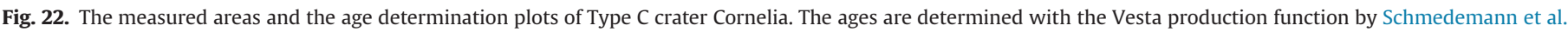
(2012). See also Table 2 for measurement details.

influences manifest at different impact angles, impact directions (relative to the slope), gravity conditions, and impact velocities. While the latter two are reasonably well constrained for Vesta, the angle and direction of impact for every single crater are unknown. Information about the trajectory (or at least the impact direction) is often inferred directly from asymmetries in the crater shape or ejecta deposits. This is only possible when assuming that the impact crater was generated on a (more or less) flat surface. While this assumption might be applicable for craters on many planetary surfaces, it is certainly not valid for the rough terrain on Vesta. Therefore we cannot infer the impact direction and angle for craters on Vesta, such as Helena. Without having this information in a quantitative way, trying to "exactly" reproduce the shape of a given crater would be an incredibly extreme effort (mainly based upon "try and error" approaches). That is the reason why we do not try to model "Helena", "Antonia", or any of the other craters listed in the manuscript directly. Instead, we just want to investigate, whether the asymmetries as described above can be - in principle - explained by the existence of a slope.

Based on the setup described in Section 2.2, we performed simulations of $1-\mathrm{km}$ sized projectiles impacting into slopes of $45^{\circ}$ inclination. We selected various impact angles and different impact positions (at the bottom, at the top, or in the center of the slope). We found that the asymmetric shape of the craters can be reproduced if the projectile hits the slope at the bottom and the impactor trajectory is directed towards the slope with an oblique angle of incidence (here: $15^{\circ}$ ), as illustrated in Fig. 24a. Explaining all different effects of slopes in general is beyond the scope of this paper. The simulations, however, provide a reasonable explanation for the formation of the asymmetries in the ejecta blanket (less ejecta uphill, mass accumulation downhill) and the crater shape (e.g. sharp edge uphill, smooth rim downhill). In the following discussion, we will therefore limit our description of the cratering process to this special case. 

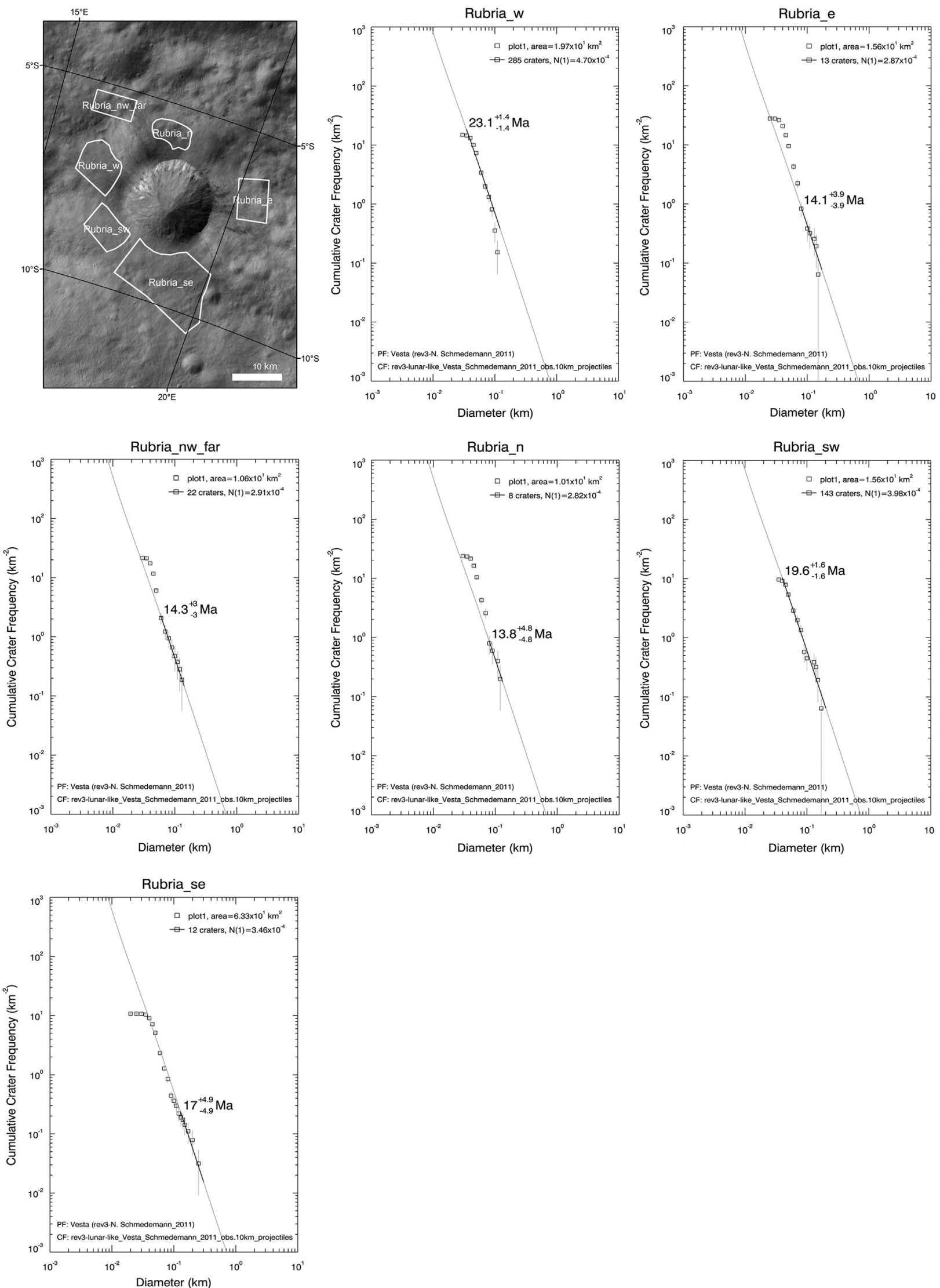

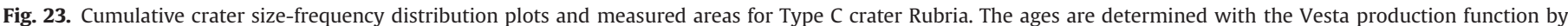
Schmedemann et al. (2012). See also Table 2 for measurement details. 

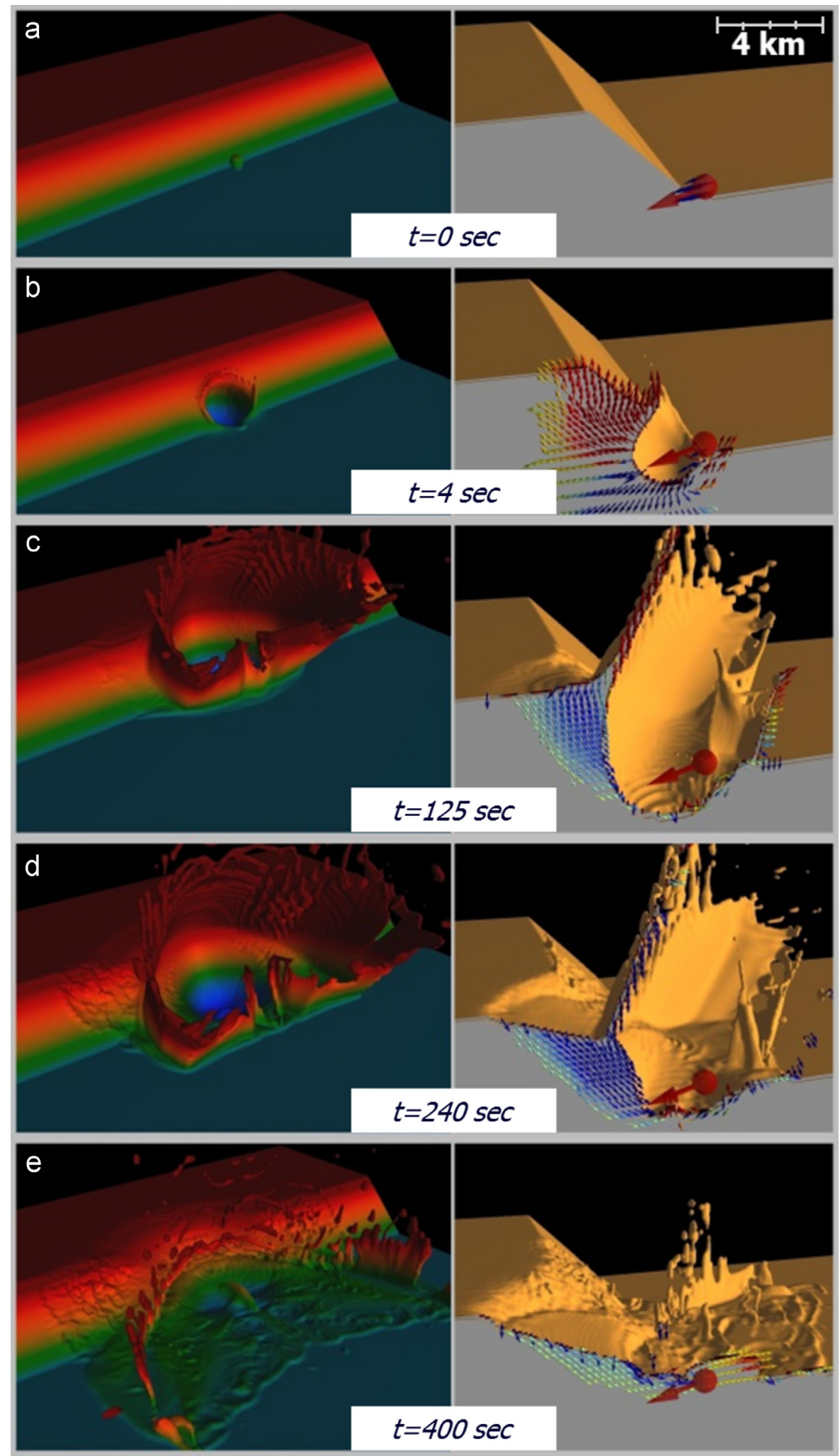

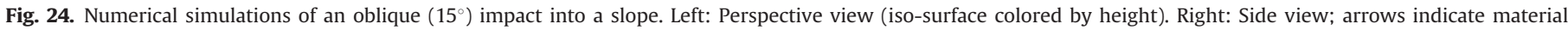
motion.

Fig. 24 shows a series of different time steps for this impact event. The images in the left column show a perspective view. The surface is colored by its initial height. The right column shows the same simulation from a lateral view. Arrows illustrate the direction of material motion (red: upwards material motion; blue: downward motion).
Until the end of the excavation stage, the cratering process is dominated by inertial forces. At this stage, gravitational forces are too low to significantly influence the cratering process. Therefore, early crater growth on a slope is quite similar to a comparable impact on a planar surface (see Fig. 24b). Note that the impact angle is measured from with respect to a horizontal plane and not 
to a slope. A projectile which impacts a slope of $45^{\circ}$ inclination at an impact angle of $15^{\circ}$ (measured from horizontal; impact angle measured from slope: $30^{\circ}$ ) would form the same cavity as the same impact at an angle of $30^{\circ}$ on a planar target.

In the continuing cratering process (Fig. 24c), however, gravity plays a more important role. The angle of the ejecta curtain, in particular in the downrange (uphill) direction, becomes significantly influenced by the slope. In contrast to hypervelocity impacts on planar targets, the downrange ejecta curtain is oriented towards the crater center (Fig. 24c-e). Once the ejecta curtain collapses material is deposited inside the crater. At steep slopes and/or low impact angles, it is also possible that material from the uphill ejecta curtain is deposited outside of the crater in downhill direction. This overlays the deposit of ejecta from the initial up-range ejecta curtain, as shown in Fig. 24e and f. This mechanism explains why few or no ejecta deposits can be observed uphill of most of the types of asymmetric craters.

The gravitational forces (even the relatively low ones observed on Vesta) cause a crater collapse that is directed downhill, as shown in Fig. 24c. Therefore, sagging of the uppermost material from the slope towards the crater center is observed, which results in a sharp edge of the crater in the uphill direction. This agrees well with the observations of these types of craters. The slumped material accumulates inside the crater. If the momentum of material motion is high enough, the accumulation might take place even in the downhill direction outside of the crater, as shown in Fig. 24e and f and the observations presented in Section 3 (see especially Fig. 2).

In conclusion, the present work indicates that the three prominent features of the asymmetric craters on Vesta, namely (a) a sharp edge uphill, (b) a smooth rim and material accumulation downhill, and (c) little or no ejecta deposits uphill, can be produced (under certain conditions) by an oblique impact into a slope. Hence, we conclude that topography is the main cause for the asymmetries observed in these craters on Vesta.

\section{Conclusion and outlook}

This study is the first one to examine the formation craters with an asymmetrical shape on Vesta. The performed crater size-frequency measurements comparing surrounding surfaces, ejecta deposits and crater interiors reveal, within measurement and cratering chronology model uncertainties, similar ages indicating that the deposits were most likely directly formed by the impact. We were able to demonstrate that topography is the most likely cause for these asymmetries. Furthermore our age determination results agree quite well with the numerical simulations, showing that the slope prevents the deposition of ejected material in uphill direction and results in a larger accumulation of ejecta within the crater and on the downhill crater rim. Understanding the formation of asymmetric craters on Vesta is crucial for understanding the role of topographic effects and the formation of similar crater shapes on bodies without any erosional or tectonical processes. It is also crucial for mapping and interpreting impact processes on planetary surfaces.

Further studies on this topic have to be conducted. We are planning to continue intense and quantitative modeling of impacts into surfaces with a wide range in topography as well as detailed investigations of crater slope angles and surface slope angles to prove how the crater slope and shape correlate with topography. Further studies will also include comparable studies on the Moon and other Asteroids.

\section{Acknowledgments}

We thank the Dawn team for the development, cruise, orbital insertion, and operations of the Dawn spacecraft at Vesta. Dawn data are archived with the NASA Planetary Data System. D. Elbeshausen has been supported by the Helmholtz-Alliance HA-203/"Planetary Evolution and Life" by the Helmholtz-Gemeinschaft Deutscher Forschungszentren (HGF).

\section{References}

Arvidson, R.E., Boyce, J., Chapman, C., Cintala, M., Fulchignoni, M., Moore, H. Neukum, G., Schultz, P., Soderblom, L., Strom, R., Woronow, A., Young, R., 1979. Group, C.A.T.W., 1979. Standard techniques for presentation and analysis of crater size-frequency data. Icarus 37, 467-474.

Benson, D.J., 2002. Volume of fluid interface reconstruction methods for multimaterial problems. Appl. Mech. Rev. 55, 151.

Bogard, D.D., 2011. K-Ar ages of meteorites: clues to parent-body thermal histories Chem. der Erde/Geochem. 71, 207-226.

Bogard, D.D., Garrison, D.H., 2003. 39Ar-40Ar ages of eucrites and thermal history of asteroid 4 Vesta. Meteorit. Planet. Sci. 38, 669-710.

Bottke, W.F., Durda, D.D., Nesvorný, D., Jedicke, R., Morbidelli, A., Vokrouhlický, D. Levison, H.F., 2005. Linking the collisional history of the main asteroid belt to its dynamical excitation and depletion. Icarus 179, 63-94.

Chapman, C.R., Ryan, E.V., Merline, W.J., Neukum, G., Wagner, R., Thomas, P.C., Veverka, J., Sullivan, R.J., 1996a. Cratering on Ida. Icarus 120, 77-86.

Chapman, C.R., Veverka, J., Belton, M.J.S., Neukum, G., Morrison, D., 1996b. Cratering on Gaspra. Icarus 120, 231-245.

Collins, G.S., Melosh, H.J., Ivanov, B.A., 2004. Modeling damage and deformation in impact simulations. Meteorit. Planet. Sci. 39, 217-231.

Collins, G.S., Morgan, J., Barton, P., Christeson, G.L., Gulick, S., Urrutia, J., Warner, M. Wünnemann, K., 2008. Dynamic modeling suggests terrace zone asymmetry in the Chicxulub crater is caused by target heterogeneity. Earth Planet. Sci. Lett. $270,221-230$.

Davison, T.M., Collins, G.S., Elbeshausen, D., Wünnemann, K., Kearsley, A., 2011. Numerical modeling of oblique hypervelocity impacts on strong ductile targets. Meteorit. Planet. Sci. 46, 1510-1524.

Denevi, B.W., Blewett, D.T., Buczkowski, D.L., Capaccioni, F., Capria, M.T., De Sanctis M.C., Garry, W.B., Gaskell, R.W., Le Corre, L., Li, J.-Y., Marchi, S., McCoy, T.J. Nathues, A., O'Brien, D.P., Petro, N.E., Pieters, C.M., Preusker, F., Raymond, C.A., Reddy, V., Russell, C.T., Schenk, P., Scully, J.E.C., Sunshine, J.M., Tosi, F., Williams, D.A., Wyrick, D., 2012. Pitted terrain on Vesta and implications for the presence of volatiles. Science 338, 246-249.

Elbeshausen, D., Wünnemann, K., Collins, G.S., 2009. Scaling of oblique impacts in frictional targets: Implications for crater size and formation mechanisms. Icarus 204, 716-731.

Elbeshausen, D., Wünnemann, K., 2011. The effect of target topography and impact angle on crater formation - insight from 3D numerical modelling. In: Lunar and Planetary Institute Science Conference Abstracts, p. 1778.

Elbeshausen, D., Wünnemann, K., Sierks, H., Vincent, J.B., Oklay, N., 2012. The effect of topography on the impact cratering process on Lutetia. In: Lunar and Planetary Institute Science Conference Abstracts, p. 1867.

Gault, D.E., Wedekind, J.A., 1978. Experimental studies of oblique impact. In: Lunar and Planetary Institute Science Conference Abstracts, pp. 374-376.

Gueyffier, D., Li, J., Nadim, A., Scardovelli, R., Zaleski, S., 1999. Volume-of-fluid interface tracking with smoothed surface stress methods for three-dimensional flows. J. Comput. Phys. 152, 423-456.

Gulick, S.P.S., Barton, P.J., Christeson, G.L., Morgan, J.V., McDonald, M., MendozaCervantes, K., Pearson, Z.F., Surendra, A., Urrutia-Fucugauchi, J., Vermeesch, P.M. Warner, M.R., 2008. Importance of pre-impact crustal structure for the asymmetry of the Chicxulub impact crater. Nat. Geosci. 1, 131-135.

Gurov, E.P., Koeberl, C., Yamnichenko, A., 2007. El'gygytgyn impact crater, Russia: structure, tectonics, and morphology. Meteorit. Planet. Sci., 42; , pp. 307-319.

Harlow, F.H., Amsden, A.A., 1971. A numerical fluid dynamics calculation method for all flow speeds. J. Comput. Phys. 8, 197.

Hiesinger, H., Head, J.W., Wolf, U., Jaumann, R., Neukum, G., 2002. Lunar mare basalt flow units: thicknesses determined from crater size-frequency distributions. Geophysical Research Letters 29 (89-81).

Hirt, C.W., Amsden, A.A., Cook, J.L., 1974. An arbitrary lagrangian-eulerian computing method for all flow speeds. J. Comput. Phys. 14, 227.

Hirt, C.W., Nichols, B.D., 1981. Volume of fluid/VOF/method for the dynamics of free boundaries. J. Comput. Phys. 39, 201-225.

Holden, N.E., Bonardi, M.L., De Bièvre, P., Renne, P.R., Villa, I.M., 2011. IUPAC-IUGS common definition and convention on the use of the year as a derived unit of time (IUPAC Recommendations 2011). Pure Appl. Chem. 83, 1159-1162.

Holsapple, K.A., 1980. The equivalent depth of burst for impact cratering. In: Bedini, S.A. (Ed.), Lunar and Planetary Science Conference Proceedings, pp. 2379-2401.

Isaacson, P.J., Pieters, C.M., 2009. Northern imbrium noritic anomaly. J. Geophys Res. (Planets) 114, 9007.

Ivanov, B., 2008. Size-frequency distribution of asteroids and impact craters: estimates of impact rate. In: Adushkin, V.V. (Ed.), Catastrophic Events Caused by Cosmic Objects, p. 91.

Ivanov, B.A., 2001. Mars/Moon cratering rate ratio estimates. Space Sci. Rev. 96, $87-104$

Ivanov, B.A., Neukum, G., Wagner, R., Rickman, H., 2001. Size-frequency distributions of planetary impact craters and asteroids. In: Marov, M.Y. (Ed.), 2001. Astrophysics and Space Science Library, pp. 1-34. 
Jaumann, R., Williams, D.A., Buczkowski, D.L., Yingst, R.A., Preusker, F., Hiesinger, H., Schmedemann, N., Kneissl, T., Vincent, J.B., Blewett, D.T., Buratti, B.J., Carsenty, U., Denevi, B.W., De Sanctis, M.C., Garry, W.B., Keller, H.U., Kersten, E., Krohn, K., Li, J.-Y., Marchi, S., Matz, K.D., McCord, T.B., McSween, H.Y., Mest, S.C., Mittlefehldt, D.W., Mottola, S., Nathues, A., Neukum, G., O'Brien, D.P., Pieters, C.M., Prettyman, T.H., Raymond, C.A., Roatsch, T., Russell, C.T., Schenk, P., Schmidt, B.E., Scholten, F., Stephan, K., Sykes, M.V., Tricarico, P., Wagner, R., Zuber, M.T., Sierks, H., 2012. Vesta's shape and morphology. Science 336 687-690.

Kneissl, T., Schmedemann, N., Walter, S., Williams, D., Garry, W.B., Yingst, A., Reddy, V., Jaumann, R., Krohn, K., Preusker, F., Roatsch, T., Buczkowski, D., Raymond, C. A., Russell, C.T., 2013. Prominent impact craters in the Av-13 Quadrangle Tuccia on Vesta - morphology, degradation, and ages of Tuccia, Eusebia, Vibidia, Galeria, and Antonia. In: Lunar and Planetary Institute Science Conference Abstracts.

Kneissl, T., van Gasselt, S., Neukum, G., 2011. Map-projection-independent crate size-frequency determination in GIS environments-new software tool for ArcGIS. Planet. Space Sci. 59, 1243-1254.

Marchi, S., Massironi, M., Vincent, J.-B., Morbidelli, A., Mottola, S., Marzari, F., Küppers, M., Besse, S., Thomas, N., Barbieri, C., Naletto, G., Sierks, H., 2012a. The cratering history of asteroid (21) Lutetia. Planet. Space Sci. 66, 87-95.

Marchi, S., McSween, H.Y., O'Brien, D.P., Schenk, P., De Sanctis, M.C., Gaskell, R. Jaumann, R., Mottola, S., Preusker, F., Raymond, C.A., Roatsch, T., Russell, C.T. 2012b. The violent collisional history of asteroid 4 Vesta. Science 336, 690.

Marchi, S., Mottola, S., Cremonese, G., Massironi, M., Martellato, E., 2009. A new chronology for the Moon and Mercury. Astron. J. 137, 4936-4948.

Massironi, M., Cremonese, G., Marchi, S., Martellato, E., Mottola, S., Wagner, R.J. 2009. Mercury's geochronology revised by applying Model production function to Mariner 10 data: geological implications. Geophys. Res. Lett. 36, 21204.

Morbidelli, A., Marchi, S., Bottke, W.F., Kring, D.A., 2012. A sawtooth-like timeline for the first billion years of lunar bombardment. Earth Planet. Sci. Lett. 355, 144-151, http://dx.doi.org/10.1016/j.epsl.2012.07.037.

Neukum, G., 1983. Meteoritenbombardement und Datierung planetarer Oberflächen, Fakultät für Geowissenschaften. Ludwig-Maximilians-Universität München, München,Germany p. 186.

Neukum, G., 1984. Meteorite Bombardment and Dating of Planetary Surfaces (Ph.D. thesis). pp. 1-186.

Neukum, G. Ivanov, B.A., Hartmann, W.K., 2001. Cratering records in the inner solar system in relation to the lunar reference system. Space Sci. Rev. 96, 55-86.

Neukum, G., Ivanov, B.A., Matthews, M.S., Schumann, A.M., 1994. Crater size distributions and impact probabilities on earth from lunar, terrestrial-planet, and asteroid cratering data. In: Gehrels, T. (Ed.), Hazards Due to Comets and Asteroids, p. 359.

O'Brien, D.P., Greenberg, R., 2005. The collisional and dynamical evolution of the main-belt and NEA size distributions. Icarus 178, 179-212.

O'Brien, D.P., Marchi, S., Schenk, P., Russell, C.T., Raymond, C.A., 2012. The impact history of Vesta: developing and testing an absolute cratering chronology. In: Lunar and Planetary Institute Science Conference Abstracts, p. 2688.

Oberbeck, V.R., Pepin, R.O., Merrill, R.B., 1977. Application of high explosion cratering data to planetary problems. In: Roddy, D.J. (Ed.), Impact and Explosion Cratering: Planetary and Terrestrial Implications, pp. 45-65.

Pierazzo, E., Artemieva, N., Asphaug, E., Baldwin, E.C., Cazamias, J., Coker, R., Collins, G.S., Crawford, D.A., Davison, T., Elbeshausen, D., Holsapple, K.A., Housen, K.R.
Korycansky, K., Wünnemann, K., 2008. Validation of numerical codes for impact and explosion cratering: impacts on strengthless and metal targets. Meteorit. Planet. Sci. 43, 1917-1938.

Plescia, J.B., 2012. Impacts on sloping surfaces: lunar examples. Meteorit. Planet. Sci. Suppl 75, S5318.

Russell, C.T., Raymond, C.A., 2011. The dawn mission to Vesta and Ceres. Space Sci. Rev. 163, 3-23.

Schmedemann, N., Kneissl, T., Michael, G., Neukum, G., Nathues, A., Sierks, H. Wagner, R., Krohn, K., Reddy, V., Hiesinger, H., Jaumann, R., Raymond, C.A., Russell, C.T., 2012. Crater size-frequency distribution (CSFD) and chronology of Vesta - crater counts matching HED ages. In: Lunar and Planetary Institute Science Conference Abstracts, pp. 2544-2545.

Schmedemann, N., Kneissl, T., Ivanov, B.A., Michael, G.G., Wagner, R.J., Neukum, G., Ruesch, O., Hiesinger, H., Krohn, K., Roatsch, T., Preusker, F., Sierks, H., Jaumann, R., Reddy, V., Nathues, A., Walter, S., Neesemann, A., Raymond, C.A., Russell, C.T., 2014. Cratering record, chronology and surface ages of (4) Vesta in comparison to smaller asteroids and ages of HED meteorites, in this issue.

Schultz, P.H., 1977. Moon morphology-interpretations based on lunar orbiter photography (book review). Astrophys. Lett. 19, 31.

Sierks, H., Keller, H.U., Jaumann, R., Michalik, H., Behnke, T., Bubenhagen, F., Büttner, I., Carsenty, U., Christensen, U., Enge, R., Fiethe, B., Gutiérrez Marqués, P., Hartwig, H., Krüger, H., Kühne, W., Maue, T., Mottola, S., Nathues, A., Reiche, K.-U., Richards, M.L., Roatsch, T., Schroder, S.E., Szemerey, I., Tschentscher, M., 2011. The dawn framing camera. Space Sci. Rev. 163, 263-327.

Simonds, C.H., Kieffer, S.W., 1993. Impact and volcanism - a momentum scaling law for erosion. J. Geophys. Res. 98, 14321.

Strom, R.G., Malhotra, R., Ito, T., Yoshida, F., Kring, D.A., 2005. The origin of planetary impactors in the inner solar system. Science 309, 1847-1850.

Thompson, S.L., Lauson, H.S., 1972. Improvements in the Chart D radiationhydrodynamic CODE III: revised analytic equations of state. Technical Report SC-RR-71 0714, Sandia National Laboratory, Albuquerque, New Mexico, 118.

Tompkins, S., Pieters, C.M., 1999. Mineralogy of the lunar crust: results from Clementine. Meteorit. Planet. Sci. 34, 25-41.

Williams, D.A., O'Brien, D.P., Schenk, P.M., Denevi, B.W., Carsenty, U., Marchi, S., Scully, J.E.C., Jaumann, R., De Sanctis, M.C., Palomba, E., Ammannito, E., Longobardo, A., Magni, G., Frigeri, A., Russell, C.T., Raymond, C.A., Davison, T.M., 2013. Lobate and flow-like features on asteroid Vesta. Planet. Space Sci., this issue.

Williams, D.A., Denevi, B., Mittlefehldt, D., Mest, S., Schenk, P., Yingst, R., Buczkowski, D., Scully, J., Garry, W., McCord, T., Combe, J.-P., Jaumann, R., Pieters, C.; Nathues, A., Corre, L.L., Hoffmann, M., Reddy, V., Schäfer, M., Roatsch, T. Preusker, F., Marchi, S., Kneissl, T., Schmedemann, N., Neukum, G., Hiesinger, H., Sanctis, M. D., Ammannito, E., Frigeri, A., Prettyman, T., Russell, C. \& Raymond, C., The Geology of the Marcia quadrangle of Asteroid Vesta: assessing the effects of large, young cratersicarus, in press.

Wünnemann, K., Collins, G.S., Melosh, H.J., 2006. A strain-based porosity model for use in hydrocode simulations of impacts and implications for transient crater growth in porous targets. Icarus 180, 514-527.

Wünnemann, K., Ivanov, B.A., 2003. Numerical modelling of the impact crater depth-diameter dependence in an acoustically fluidized target. Planet. Space Sci. 51, 831-845. 